\title{
BREACH AND FULFILLMENT OF THE PSYCHOLOGICAL CONTRACT: A COMPARISON OF TRADITIONAL AND EXPANDED VIEWS
}

\author{
LISA SCHURER LAMBERT, JEFFREY R. EDWARDS, DANIEL M. CABLE \\ Kenan-Flagler Business School \\ University of North Carolina at Chapel Hill
}

\begin{abstract}
Breach and fulfillment in a psychological contract has traditionally been studied with approaches that are conceptually and methodologically limited. We compared predictions derived from the traditional view to predictions from an expanded view that maintains the distinction between promised and delivered inducements and examines their joint relationship with employee satisfaction. The traditional and expanded views were compared using longitudinal data and polynomial regression analysis. Results provided little support for the traditional view. In contrast, results supported the expanded view and revealed that relationships for breach and fulfillment are more complex than previously suggested. Specifically, satisfaction depended on whether breach represented deficient or excess inducements and the particular inducement under consideration. Moreover, satisfaction was more strongly related to delivered inducements than promised inducements. These results question basic tenets of psychological contract research and indicate new avenues for research that build on the expanded view developed in this article.
\end{abstract}

The type of relationship that develops between employees and organizations is fundamental to organizational success and survival as well as employee well being. This relationship also forms the foundation of many streams of organizational behavior research, including research into the psychological contract. A psychological contract is an employee's beliefs regarding the mutual obligations between the employee and an employer (Rousseau, 1989; Rousseau \& Tijoriwala, 1998). These beliefs entail perceptions of the inducements (e.g., pay, recognition) promised by an employer compared to the inducements delivered by the employer. When a psychological contract is violated, employees may experience anger, distrust, reduced loyalty and commitment, and increased propensity to leave the organization (Robinson, 1996; Robinson \& Morrison, 2000; Robinson \& Rousseau, 1994).

We thank two anonymous reviewers for their helpful comments.

Earlier versions of this paper were presented at the Annual Conference of the Society for Industrial and Organizational Psychology, New Orleans, LA, 2000, and the Annual Meeting of the Academy of Management, Denver, CO, 2002.

Correspondence and requests for reprints should be addressed to Lisa Schurer Lambert, CB\#3490, McColl Building, Chapel Hill, NC 27599-3490; lisa_lambert@unc.edu.

COPYRIOHT @ 2003 PERSONNEL PSYCHOLOGY, INC. 
Traditionally, psychological contract research has emphasized situations in which inducements are deficient, meaning the inducements received by the employee are less than what the employer promised. Although research on deficient inducements has yielded important findings, it provides a limited view of psychological contract breach and fulfillment in four respects. First, breach can occur not only for deficient inducements, but also for excess inducements, meaning that the employee has received more inducements than promised (Conway \& Briner, 2002; Coyle-Shapiro \& Kessler, 2000; Turnley \& Feldman, 2000). Second, an employee's reaction to receiving deficient or excess inducements may depend on the specific inducement under consideration (e.g., pay vs. recognition). For instance, an employee who receives deficient inducements is likely to feel dissatisfaction, whereas an employee who receives excess inducements may experience satisfaction or dissatisfaction depending on the inducement involved (Adams, 1965; Lawler, 1981; Locke, 1976). Third, breach and fulfillment do not convey the absolute levels of promised and delivered inducements. For instance, knowing that an employee received promised levels of inducements does not indicate whether promised and received inducements were low or high in an absolute sense. Fourth, focusing solely on breach conceals the relative effects of delivered and promised inducements. These effects may differ, as indicated by research showing that employee reactions are more strongly related to work experiences than standards such as expectations (Hom, Griffeth, Palich, \& Bracker, 1999; Irving \& Meyer, 1994) or desires (Edwards \& Rothbard, 1999). When applied to psychological contract research, these findings suggest that outcomes may be more strongly related to delivered inducements than promised inducements.

Traditional psychological contract research is also limited by methods used to operationalize breach. With few exceptions, breach is operationalized by collapsing promised and delivered inducements into a single entity using one of three methods. One method involves subtracting what was promised from what was delivered, yielding an algebraic difference score (Coyle-Shapiro \& Kessler, 2000; Guzzo, Noonan, \& Elron, 1994; Porter, Pearce, Tripoli, \& Lewis, 1998; Robinson, 1996). A second method asks employees to report the extent to which delivered amounts exceed or fall short of promised amounts (Guest \& Conway, 2002; Lester, Turnley, Bloodgood, \& Bolino, 2001; Turnley, Bolino, Lester, \& Bloodgood, 2003; Turnley \& Feldman, 1999, 2000). This method is analogous to subtracting promised inducements from delivered inducements but elicits this difference directly from the respondent. However, for both methods, the resulting score represents a directional comparison between delivered and promised inducements. 
The third method asks employees the extent to which their psychological contract was fulfilled, then reverses these scores to indicate breach (Coyle-Shapiro \& Kessler, 2000; Herriot, Manning, \& Kidd, 1997; Kickul, Lester, \& Finkl, 2002; Robinson \& Morrison, 1995; Robinson \& Morrison, 2000; Robinson \& Rousseau, 1994). Low scores imply that delivered and promised inducements are equal, such that the psychological contract is fulfilled. High scores indicate that delivered inducements differ from promised levels without specifying the direction of the difference, given that lack of fulfillment could mean that delivered inducements either exceed or fall short of promised inducements. Hence, these scores represent the perceived nondirectional comparison between delivered and promised inducements. The directional and nondirectional approaches both disregard absolute levels of delivered and promised inducements, and the nondirectional approach does not distinguish between deficient and excess inducements. Moreover, both approaches represent a computed or perceived difference between delivered and promised inducements and are, therefore, susceptible to methodological problems with difference scores (Edwards, 1994; Johns, 1981).

The limitations of traditional psychological contract research can be overcome by adopting an expanded view of the psychological contract. This expanded view has several important features. First, it broadens the definition of breach to encompass situations where delivered inducements either exceed or fall short of promised levels. Second, it addresses how the outcomes of breach may differ depending on whether breach entails deficient or excess inducements and recognizes that the effects may depend on the specific inducements involved. For example, an employee who received excess pay may experience higher levels of satisfaction, but an employee who received excess task variety may be overwhelmed and distracted from other responsibilities. Third, it incorporates the absolute levels of promised and delivered inducements because employees who are promised and receive high levels of rewards may respond more positively than employees who are promised and receive low levels of rewards (Edwards \& Harrison, 1993; Imparato, 1972; Lawler, 1981). Finally, it uses methods that capture the inherent three-dimensional relationship of promised and delivered inducements with outcomes, thereby avoiding problems with difference scores and capturing important complexities regarding the effects of psychological contract breach and fulfillment (Edwards, 1994; Edwards \& Parry, 1993).

This study investigates the effects of breach and fulfillment on outcomes by comparing the traditional view of psychological contract research to the expanded view described above. To this end, we first examine the traditional view by identifying predictions based on conceptual work on psychological contracts and implied by difference score ap- 
proaches for deficiency, excess, and absolute levels of fulfillment. We compare these predictions to those developed using the expanded view, which draws from theories concerning the cognitive comparison of rewards to internal standards and combines predictions for deficiency, excess, and fulfillment to yield hypothesized three-dimensional surfaces relating promised and delivered inducements to outcomes. We then report evidence bearing on these comparisons, using difference scores to operationalize the traditional view, and polynomial regression and response surface methodology for the expanded view (Edwards, 1994; Edwards \& Parry, 1993). Our results reveal that the relationships of breach and fulfillment with outcomes are indeed more complex than suggested by traditional psychological contract research. These results demonstrate the value of adopting the expanded view of the psychological contract and offer new insights regarding the effects of breach and fulfillment.

\section{Theory and Hypotheses}

As noted above, one assertion of the expanded view is that the effects of psychological contract breach and fulfillment depend upon the type of inducement under consideration. We selected six inducements that are central to how employees evaluate their work experiences and are prevalent in psychological contract research (Coyle-Shapiro \& Kessler, 2000; Kickul, 2001; Robinson, Kraatz, \& Rousseau, 1994; Turnley \& Feldman, 1999). Pay is a primary reward for employees' time and effort (Lawler, 1981; Simon, 1951) and recognition from supervisors conveys approval and indicates possible future rewards, which may increase an employee's feelings of predictability and trust (Mayer, Davis, \& Schoorman, 1995; Miller, 1981; Stajkovic \& Luthans, 2001). Opportunities to form relationships with others at work satisfy fundamental human needs by creating connections with other people and offering social support (Baumeister \& Leary, 1995; Cohen \& McKay, 1984). Variety enhances the possibilities for meaningful and enriched work experiences (Hackman \& Oldham, 1975). Finally, career training and opportunities for skill development enhance future employability and can also yield intrinsic rewards (Hackman \& Oldham, 1975; Rousseau, 1997; Sullivan, 1999; White, 1959).

For each inducement, we focused on the outcome of employees' satisfaction with their jobs, for two reasons. First, satisfaction is a general attitude that captures both positive and negative affect and is related to more specific affective reactions often considered in psychological contract research (Smith, Kendall, \& Hulin, 1969; Weiss \& Cropanzano, 1996). Second, a wide body of research in organizational behavior and psychological contracts has linked satisfaction to other attitudinal 
and behavioral outcomes, facilitating comparisons between our results and those from prior research (Judge, Thoresen, Bono, \& Patton, 2001; Kickul et al., 2002; Larwood, Wright, Desrochers, \& Dahir, 1998; Organ \& Ryan, 1995; Robinson \& Rousseau, 1994).

\section{Traditional Views of Breach and Fulfillment}

Traditional psychological contract research is based on one of two complementary theoretical arguments. The first is that deficiency leads to negative outcomes. Deficiency deprives employees of valued rewards; engenders feelings of distributive and procedural injustice, distrust, and betrayal; and leads to reduced contributions (Coyle-Shapiro, 2002; Kickul, 2001; Robinson \& Morrison, 1995; Robinson \& Morrison, 2000; Robinson \& Rousseau, 1994; Rousseau, 1989; Turnley et al., 2003; Turnley \& Feldman, 1999, 2000). The second argument is that fulfillment leads to positive outcomes. Fulfillment creates feelings of being valued, increases trust, and leads to positive outcomes for the employee and the organization (Conway \& Briner, 2002; Coyle-Shapiro \& Kessler, 2000; Robinson \& Morrison, 1995). These arguments are complementary in that decreased deficiency is conceived as increased fulfillment, and vice versa.

Theoretical arguments regarding the effects of both deficiency and fulfillment address situations where delivered inducements fall short of promised levels. In contrast, little conceptual attention has been devoted to situations where delivered inducements exceed promised levels. However, the predicted effects of excess inducements implied by the traditional view can be inferred from the methods used to test breach and fulfillment. As described earlier, hypothesis testing in psychological contract research has been dominated by difference score approaches. Each approach entails a mathematical statement that implies a hypothesis. Specifically, the directional approach implies a linear relationship such that satisfaction increases as delivered inducements increase toward promised inducements and continues to increase as delivered inducements exceed promised inducements. The directional approach has also been operationalized by asking respondents to compare promised and delivered terms by implicitly or explicitly calculating their algebraic difference. As such, this measure has been viewed as a subjective version of an algebraic difference score (Turnley \& Feldman, 2000) and, therefore, implies that satisfaction increases as delivered inducements approach and exceed promised inducements. In contrast, the nondirectional approach to fulfillment implies that satisfaction is greatest when delivered inducements equal promised inducements and declines as delivered amounts deviate from promised inducements in either direction. 
The relationship implied by this approach is consistent with the theoretical arguments put forth by researchers who hypothesize that fulfillment leads to positive outcomes and deviations from fulfillment constitute breach (Coyle-Shapiro \& Kessler, 2000; Robinson, 1996; Robinson \& Rousseau, 1994). By extension, this reasoning treats excess inducements as a deviation from fulfillment and paradoxically implies that the effects of excess inducements are negative. This conceptualization of fulfillment may be represented by a squared difference score, which stipulates that satisfaction is maximized when the contract is fulfilled and decreases as deviations from fulfillment increase.

Traditional psychological contract research does not address variation in outcomes depending on the absolute levels of promised and delivered inducements. However, these effects can again be inferred from the approaches used to test breach and fulfillment. Because both the directional and nondirectional approaches represent difference scores, they imply that outcomes are affected only by the relative comparison of promised and delivered inducements. Accordingly, both approaches suggest that satisfaction does not depend on the absolute levels of psychological contract terms, such that satisfaction will be the same regardless of whether fulfillment represents low versus high levels of promised and delivered inducements. We treat this null effect as an assumption rather than a hypothesis, given that it has not been explicitly stated in traditional psychological contract research. As will be seen, we later report evidence that challenges this assumption.

In summary, there are two variations of the traditional view on breach and fulfillment. Both approaches imply that the effects of deficiency are negative, but they differ with respect to the effects of excess. The algebraic difference score and direct measure of breach imply that effects of excess will be positive, whereas the direct measure of fulfillment suggests that effects of excess will be negative. These approaches lead to the following hypotheses:

Hypothesis 1: Satisfaction will increase as delivered inducements increase toward promised inducements and continue to increase as delivered inducements exceed promised inducements.

Hypothesis 2: Satisfaction will increase as delivered inducements increase toward promised inducements and decrease as delivered inducements exceed promised inducements.

Hypotheses 1 and 2 offer opposite predictions regarding the effects of excess inducements, and, therefore, supporting one hypothesis necessarily rejects the other hypothesis. This tension should be kept in mind when interpreting tests of these hypotheses later in this article.

The predictions indicated by Hypotheses 1 and 2 are illustrated in Figures $1 \mathrm{a}$ and $1 \mathrm{~b}$. In both figures, the vertical axis represents satisfac- 

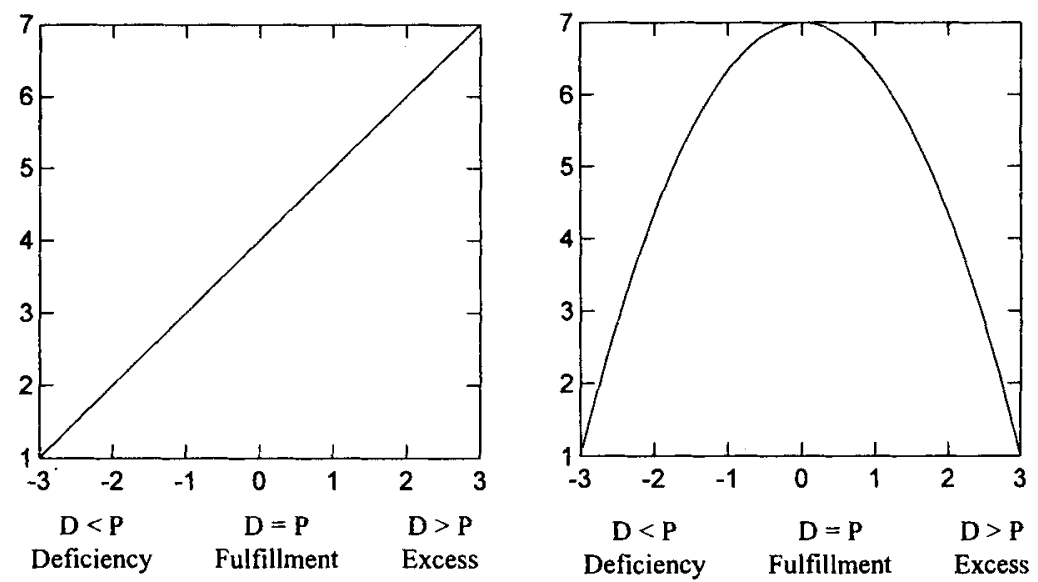

Figure 1: Traditional View Predictions for Breach and Fulfillment.

tion and the horizontal axis depicts the difference between delivered and promised inducements, ranging from deficiency at the far left, proceeding to fulfillment at the midpoint, and continuing to excess at the far right. Predictions based on the algebraic difference and the direct measure of breach are illustrated by the positive linear relationship in Figure 1a, and the prediction derived from the direct measure of fulfillment is captured by the inverted $U$-shaped relationship in Figure $1 b$.

Traditional approaches for assessing breach and fulfillment combine the comparison of promised and delivered inducements into a single score. As such, these methods suffer from the conceptual and methodological problems associated with difference scores (Edwards, 1994; Johns, 1981). In particular, difference score methods confound the effects of promised and delivered inducements, thereby implying that both components contribute equally to employee satisfaction. However, prior research on the comparison of work experiences to standards such as expectations, preferences, and referent others indicates that work experiences, which includes how employees have been rewarded, have greater effects than standards on various outcomes (Hom et al., 1999; Irving \& Meyer, 1994; Rice, Phillips, \& McFarlin, 1990). These results may generalize to psychological contract research, such that delivered inducements have stronger effects than promised inducements. In addition, difference scores impose constraints on the effects of promised and delivered inducements that may not be justified. For instance, the algebraic difference score and direct measure of breach constrain the effects of de- 
livered and promised inducements to be equal in magnitude but opposite in sign. This constraint is frequently rejected in studies that examine the assumptions underlying algebraic difference scores (Antonioni \& Park, 2001; Atwater, Ostroff, Yammarino, \& Fleenor, 1998), including studies of the relationships of work experience and standards with satisfaction (Edwards \& Harrison, 1993). In contrast, the direct measure of fulfillment constrains the effects of promised and delivered inducements to a curvilinear relationship such that satisfaction is maximized at the point where promised and delivered inducements are equal. Yet, depending on the inducement involved, satisfaction may be maximized when delivered inducements exceed promised inducements (Edwards, Caplan, \& Harrison, 1998; Locke, 1976), and dissatisfaction may be greater for deficient inducements than for excess inducements (Edwards \& Rothbard, 1999). Third, difference score methods focus on the comparison of promised and delivered inducements and disregard their absolute level, thereby implying that satisfaction is solely a function of delivered inducements relative to promised inducements. However, satisfaction may be greater when promised and delivered inducements are both high than when both are low (Edwards \& Rothbard, 1999; Imparato, 1972; Lawler, 1971). Finally, and perhaps most fundamentally, difference score methods reduce the inherently three-dimensional relationship of promised and delivered inducements with outcomes to two dimensions. This narrows the conceptualization of breach and fulfillment and neglects the basic fact that promised inducements, delivered inducements, and outcomes are three distinct constructs.

\section{Expanded View of Breach and Fulfillment}

In contrast to the traditional view, the expanded view proposed in this paper considers the joint effects of promised and delivered inducements on satisfaction. We begin by focusing on breach and fulfillment and then consider the relative magnitudes of the effects of promised and delivered inducements. Breach is conceptualized as a continuum ranging from deficiency where delivered inducements fall short of promised levels to fulfillment where delivered inducements equal promised levels, to excess where delivered inducements exceed promised levels. Fulfillment is also a continuum where delivered and promised inducements range from low to high levels with the stipulation that delivered and promised inducements are equal. Together, breach and fulfillment represent the two critical axes in a plane defined by promised and delivered inducements and constitute the focus of our hypotheses.

Breach. To develop hypotheses regarding breach, we consider deficiency and excess separately and then combine them into statements 
regarding variation in outcomes along the breach line. Consistent with prior research, we propose that when delivered inducements fall short of promised inducements, employees are likely to feel low levels of satisfaction. Deficient inducements should lead to low levels of satisfaction because promised inducements constitute a standard that employees are likely to consider desirable or acceptable (Atiyah, 1981; Goodman, 1974; Kulik \& Ambrose, 1992). Therefore, when received inducements fall short of promised levels, it is likely that an employee's desires are unfulfilled and dissatisfaction will result (Pinder, 1998). This reasoning is consistent with research on discrepancy theories of satisfaction, which has consistently found that satisfaction is low when received outcomes fall short of desires (Diener, Suh, Lucas, \& Smith, 1999; Edwards, 1991; Locke, 1976).

Unlike deficient inducements, excess inducements have received little attention in the psychological contract literature. As noted previously, empirical psychological contract research implies that excess inducements may increase or decrease satisfaction, but the conditions under which these different effects will occur have not been addressed. We argue that the effects of excess inducements on satisfaction depend on the type of inducement. Drawing from research on job satisfaction (Locke, 1976) and person-environment fit (Edwards et al., 1998), we posit that excess inducements will increase satisfaction when they can be applied to a wide range of employee needs and desires (Edwards et al., 1998). For instance, pay fulfills both material and psychological needs, given that higher levels of pay signify achievement and status. In contrast, we reason that excess inducements will decrease satisfaction when they interfere with the fulfillment of needs and desires, such that high levels of inducements become detrimental to the employee (Edwards et al., 1998; Warr, 1994). For example, increasing task variety beyond an optimal point may interfere with an employee's ability to develop proficiency on a core set of skills, thereby hindering task performance. Thus, the key distinction that determines the effects of excess inducements is whether increasing levels of inducements promote versus inhibit the fulfillment of the various needs and desires held by an employee.

Drawing from this distinction, we predict that excess pay, recognition, and relationships will increase satisfaction, given that high levels of these inducements should help fulfill a range of needs and desires. Specifically, as noted above, pay is an extrinsic reward that provides a variety of material and psychological benefits. Likewise, recognition fulfills needs for approval, esteem, and competence and implies additional inducements will be forthcoming (Mayer et al., 1995; Stajkovic $\&$ Luthans, 2001). Relationships with others provide social resources that fulfill affiliation needs and furnish support in times of stress and 
difficulty (Baumeister \& Leary, 1995; Cohen \& Wills, 1985; Coyne \& Downey, 1991). Combining these arguments for excess inducements with those for deficient inducements yields the following hypotheses for breach of pay, recognition, and relationships:

Hypothesis 3: For pay, recognition, and relationships, satisfaction will increase as delivered levels increase toward promised levels and continue to increase as delivered levels exceed promised levels.

In contrast, for variety, skill development, and career training, excess inducements should decrease satisfaction. Research suggests that there is an optimal level for these inducements, such that either high or low levels elicit negative reactions. In particular, low levels of variety are associated with boredom and lack of stimulation, whereas high levels limit proficiency on a particular set of tasks (Edwards \& Cable, 2002; Warr, 1987). Low levels of skill development signify work with few opportunities to learn and develop (Hackman \& Oldham, 1975; Hulin \& Blood, 1968), but high levels can create overload and distract attention from task performance itself (Warr, 1990). Finally, little career training hinders future employment prospects and limits the long-term relevance of a particular job (Rousseau, 1997), whereas large amounts of career training can again induce overload and detract from current task performance (Warr, 1990) and also sensitize employees to their inadequacies regarding their career preparation, leading to anxiety (Kossek, Roberts, Fisher, \& Demarr, 1998). Hence, either low or high levels of these inducements would be undesirable to the employee. This reasoning yields the following hypotheses for breach regarding variety, skill development, and career training:

Hypothesis 4: For variety, skill development, and career training, satisfaction will increase as delivered levels increase toward promised levels and will decrease as delivered levels exceed promised levels.

Fulfillment. As noted previously, psychological contract theory has presumed that, when delivered inducements match promised inducements, satisfaction remains constant regardless of whether delivered and promised inducements are low or high. This presumption is challenged by research relating person-environment fit to satisfaction, where satisfaction is often higher when actual and desired inducements are both high than when both are low (Edwards \& Harrison, 1993; Edwards \& Rothbard, 1999). The conceptual rationale for this relationship is that setting and fulfilling an ambitious standard itself represents an accomplishment that brings feelings of competence and self-esteem (White, 1959). Based on this reasoning, we suggest that employees who receive high promised levels of inducements, regardless of which inducement is involved, may draw satisfaction from the notion that they have sought 
and attained substantial inducements from an employer. Employees may be further satisfied because the employer has fulfilled an ambitious commitment to them (Gouldner, 1960; Greenberg, 1980; Kramer, 1999). For these reasons, we expect dissatisfaction to decrease as promised and delivered inducements jointly increase.

Hypothesis 5: When promised and delivered inducements are equal, satisfaction will increase as the absolute levels of promised and delivered inducements increase.

\section{Relative Effects of Promised and Delivered Inducements.}

Psychological contract research rests on the tacit assumption that the effects of promised and delivered inducements are equal in magnitude. This assumption is evident in difference score methods used to operationalize breach, which assign equal weight to promised and delivered contract terms. For instance, the directional approach forces the effects of promised and delivered inducements to be equal in magnitude but opposite in sign, due to the constraint imposed by algebraic difference scores (Edwards, 1994). However, we argue that satisfaction will exhibit stronger relationships with delivered inducements than with promised inducements, for several reasons. First, delivered elements contribute directly to employees' outcomes because what is delivered constitutes the resources available to an employee for satisfying needs. By comparison, promised elements may have an indirect effect on need fulfillment, serving primarily as a standard of comparison contrasted to the delivered elements (Tversky \& Griffin, 1991). Second, delivered inducements are concurrent with satisfaction, both of which are experienced after employment. In contrast, promised inducements occur before employment. Therefore, satisfaction should be more strongly related to delivered inducements than promised inducements simply because delivered inducements and satisfaction occur within the same time frame. This reasoning is consistent with prior research separating the effects of work experiences from the effects of the comparison standard, which show that work experiences always mattered more than the comparison standard. Findings from research on comparison standards has shown that what employees want from their jobs (Edwards \& Rothbard, 1999), what they expect (Hom et al., 1999; Irving \& Meyer, 1994), what relevant others have received (Berkowitz, Fraser, Treasure, \& Cochran, 1987; Hagerty, 2000), and what employees deserve (Rice et al., 1990), explains little of employees' outcomes. Thus, we offer the following prediction regarding the relative effects of delivered and promised inducements:

Hypothesis 6: Satisfaction will be more strongly related to delivered inducements than promised inducements. 
To test the hypotheses generated by the expanded view, it is necessary to use methods that capture the three-dimensional relationship of promised and delivered inducements with outcomes and provide formal tests of this relationship. These features are provided by polynomial regression and response surface methodology (Edwards, 1994; Edwards \& Parry, 1993). Applied to this study, polynomial regression uses measures of promised and delivered inducements and their squares and product to predict satisfaction, thereby yielding a quadratic equation. This equation represents a three-dimensional response surface that is formally analyzed by testing features of the surface corresponding to Hypotheses 3 , 4,5 , and 6 .

To illustrate the principles of polynomial regression, Figures $2 \mathrm{a}$ and 3a show three-dimensional surfaces that correspond to the twodimensional predictions based on the traditional view in Figures 1a and 1b. For the graphs in Figures $2 a$ and 3a, the vertical axis represents satisfaction and the two horizontal axes represent delivered and promised inducements. The comparison of promised and delivered terms is captured by the two-dimensional space on the floor of each graph. Through this space run two key lines. The first, labeled the breach line, represents variation in delivered inducements relative to promised inducements. Along this line, the region where delivered inducements are less than promised inducements represents deficiency, whereas the region where delivered inducements are greater than promised inducements signifies excess. The second, labeled the fulfillment line, captures variation in absolute levels of promised and delivered terms under the condition that they are equal. Figure 2a corresponds to Hypothesis 1, showing that satisfaction increases along the breach line and remains constant along the fulfillment line. Figure 3a depicts Hypothesis 2, indicating that satisfaction decreases along the breach line for both deficient and excess inducements and is constant along the fulfillment line.

The hypotheses derived from the expanded view yield predicted surfaces that are more complex than those based on the traditional view. We first consider the hypotheses for pay, recognition, and relationships. Hypothesis 3 predicted that, for these inducements, satisfaction will increase along the breach line, as indicated by the surface in Figure 2a. Hypothesis 5 stated that satisfaction will increase along the fulfillment line. This prediction adds positive slopes for both promised and delivered inducements, which transforms Figure $2 a$ into Figure $2 b$. In effect, the positive slope along the fulfillment line increases the slope for delivered inducements and decreases the slope for promised inducements. Finally, Hypothesis 6 predicted that satisfaction will be more strongly related to delivered inducements than promised inducements. This hypothesis further increases the slope of delivered inducements relative to 
a. Expanded Algebraic Difference Score

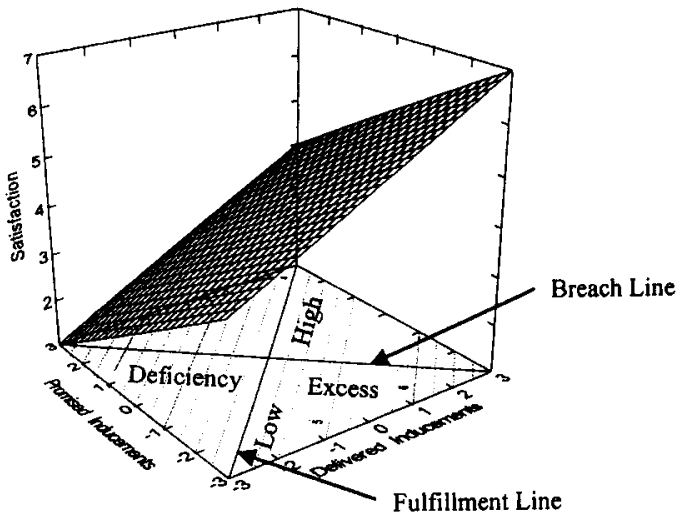

b. Slope along Fulfillment Line

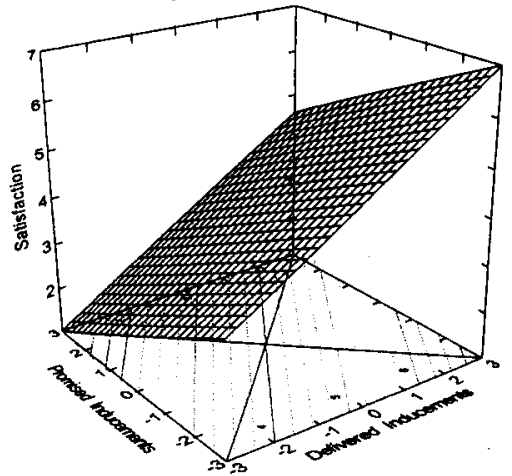

c. Predicted for Pay, Recognition and Relationships

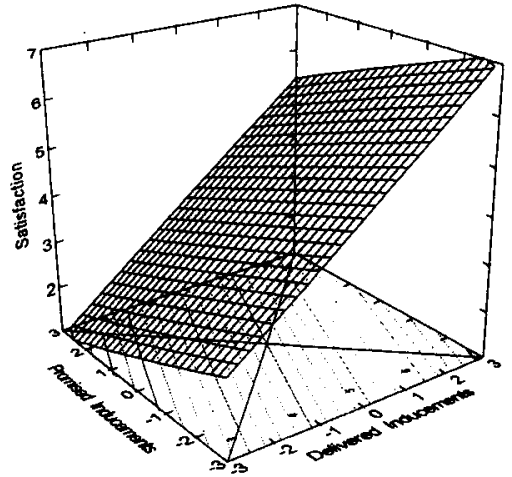

Figure 2 
a. Expanded Squared Difference Score

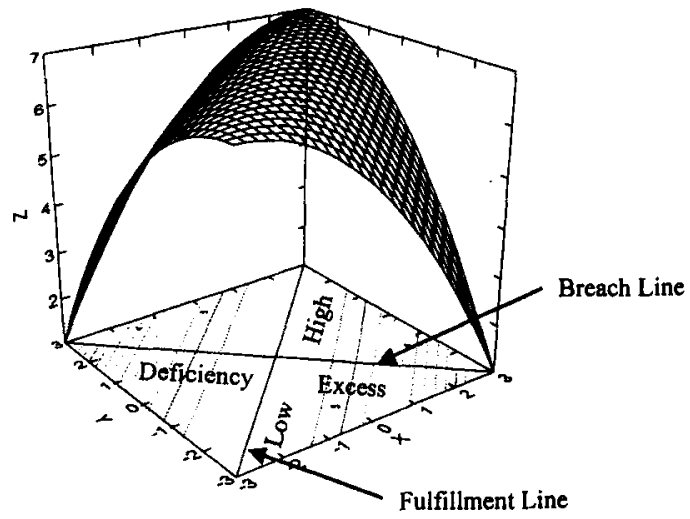

b. Slope along Fulfillment Line

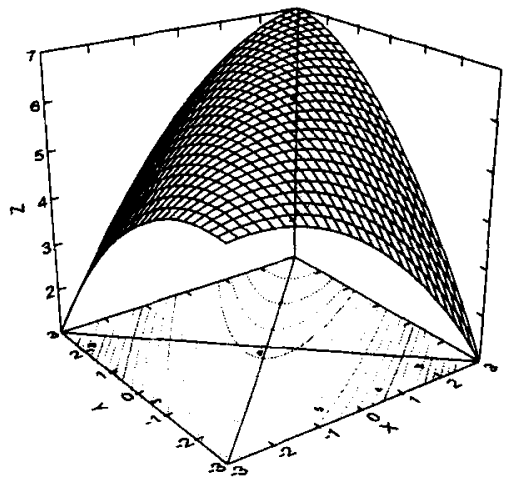

c. Predicted for Variety, Skill Development and Career Training

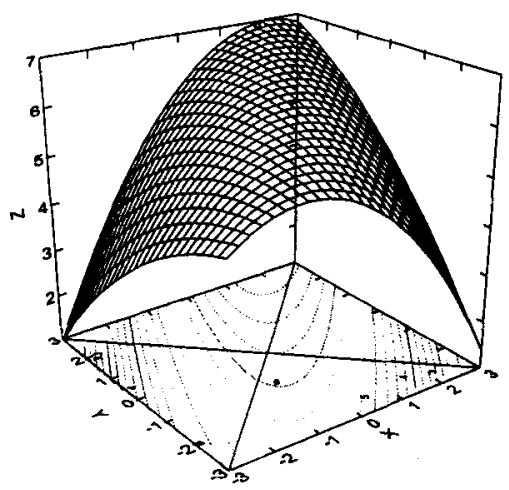

Figure 3 
promised inducements, yielding Figure $2 c$. Thus, the combined effects of the predictions in Hypotheses 3, 5, and 6 are summarized by Figure 2c.

We now turn to the hypotheses for variety, skill development, and career training. Hypothesis 4 indicated that, along the breach line, satisfaction would decrease as delivered inducements deviate from promised inducements in either direction, as shown by the surface in Figure 3a. Hypothesis 5 predicted that satisfaction will increase along the fulfillment line. When the positive slopes for delivered and promised inducements indicated by this hypothesis are added to Figure 3a, the result is Figure $3 \mathrm{~b}$. Hypothesis 6 , which stated that satisfaction will be more strongly related to delivered inducements than promised inducements, has two effects on the surface: (a) along the breach line, the maximum of the surface is shifted to the right; and (b) the surface is rotated counterclockwise. These two effects yield Figure $3 \mathrm{c}$. The heavy dashed line crossing the floor of the graph is the first principal axis of the surface, which describes the orientation of the surface in the two-dimensional space defined by promised and delivered inducements (Edwards \& Parry, 1993). Hence, the combined effects of Hypotheses 4, 5, and 6 are captured by Figure 3c.

In this study, we follow the traditional view by testing Hypotheses 1 and 2 using difference scores. Next, we use polynomial regression to test the assumptions underlying difference scores and determine whether the relationship of promised and delivered inducements with satisfaction correspond to the surfaces shown in Figures $2 \mathrm{a}$ and 3a. We then use polynomial regression to test Hypotheses 3, 4, 5, and 6 and to evaluate whether the surfaces for promised and delivered inducements correspond to Figures $2 \mathrm{c}$ and $3 \mathrm{c}$. As will be seen, these analyses indicate that difference scores conceal substantively meaningful effects of psychological contract breach and fulfillment that can be formally tested using polynomial regression.

\section{Method}

\section{Sample and Procedure}

Respondents were student employees at a large southeastern public university who were surveyed as they began employment. Respondents were employed in a variety of settings that included medical, physical and social science laboratories; botanical gardens; art galleries; libraries; and theaters. Respondents served as accounting, administrative, and research assistants; Web developers; tutors for the university and in public schools; and clerical support. These jobs provided a wide range of work experiences relevant to psychological contract investigation (Rousseau \& Schalk, 2000). Employees and supervisors negotiated terms of the 
employment relationship (although pay rates for each job were set by a central office, the number of hours worked, and, hence, the total compensation, was negotiated by employees and supervisors). Although part time, these positions were permanent and were employees' main source of income. The length of employment was typically from 1 to 4 years; either party could terminate the employment relationship at any time.

We used a 2-stage survey process. At Time 1, surveys were distributed to employees after they accepted a position but before they began work. The survey contained questions regarding promised inducements and contributions associated with the position the employee had accepted, along with questions eliciting demographic and background information. A total of 311 surveys were returned, yielding a response rate of $49 \%$. The Time 2 survey was mailed to respondents about 10 weeks after they began work. We selected this time frame as sufficient for employees to form perceptions of their work experiences, based on findings from the socialization and met expectations literature suggesting that employees evaluate their work experiences soon after hire (Bauer \& Green, 1994; Irving \& Meyer, 1994; Morrison, 1993). The Time 2 survey contained questions regarding delivered inducements and contributions and satisfaction. E-mail messages and follow-up mailings were used to increase the response rate. Of the 311 respondents who returned surveys at Time 1, 213 completed surveys at Time 2, yielding a follow-up response rate of $68 \%$. The sample consisted of respondents who completed surveys at both Time 1 and Time 2 .

Respondents ranged in age from 17 to 24 years, and $79 \%$ were women. Fifty-four percent of the sample was Caucasian, $38 \%$ was African American, and the rest was Asian, Native American, or Hispanic. Ninety-three percent of the respondents indicated they had previous paid work experience.

\section{Measures}

Inducements. Pay was measured with two items eliciting pay level (Edwards \& Rothbard, 1999) supplemented by a third analogous item that referred to "amount of money." Recognition was measured with three items adapted from the Minnesota Importance Questionnaire (MIQ; Gay, Weiss, Hendel, Dawis, \& Lofquist, 1971). A sample item is "being noticed when I do a good job." Relationships with others was measured with three items from the MIQ, the Work Values Inventory (Super, 1970), and the Work Aspect Preference Scale (Pryor, 1983). A sample item is "developing close friendships with coworkers." Variety was measured with three items adapted from MIQ, such as "doing something different every day." Skill development was measured with three items drawn from the WAPS, including "adding to the abilities you 
already have." Career training was measured with three items adapted from Welbourne, Johnson, and Erez (1998). An example is "developing skills needed for your future career."

Promised and delivered levels. At Time 1, respondents indicated how much of each inducement had been promised by the employer (i.e., "how much do you believe your employer has promised you?'). At Time 2, respondents reported the amount received from the employer (i.e., "how much have you actually received?"). All items were rated on a 7-point scale with verbal anchors ranging from $1=$ not at all to $7=$ very much.

Outcomes. Job satisfaction was measured with three items used by Edwards and Rothbard (1999) measured on a 7-point scale ranging from 1 = strongly disagree to $7=$ strongly agree. A sample item is "in general, I am satisfied with my job."

Analysis. Hypotheses were tested with regression analyses in which the dependent variable was satisfaction and the independent variables were various combinations of promised and delivered inducements, as required to operationalize the traditional and expanded views. For the traditional view, we initially used the algebraic or squared difference between promised and delivered inducements as a single independent variable. Under the traditional view, if the algebraic or squared difference score explains significant variance in the dependent variable, it would be customary to infer support for support for Hypotheses 1 or 2, respectively. We then tested the assumptions underlying the algebraic and squared difference scores using the confirmatory procedure proposed by Edwards (1994). This procedure begins by estimating an unconstrained equation corresponding to each difference score. For the algebraic difference, the unconstrained equation is linear and contains promised and delivered inducements as separate predictors. For the squared difference, the unconstrained equation is quadratic and includes promised inducements, delivered inducements, their squares, and their product as predictors. We then applied the conditions described by Edwards (1994) to determine whether: (a) the unconstrained equation explained a significant amount of variance in the dependent variable; (b) the appropriate coefficients were significant and in the direction implied by the difference score; (c) the pattern of constraints imposed by the difference score was supported; and (d) the set of terms one order higher than those in the unconstrained equation did not significantly increase the explained variance. For the expanded view, analyses were based on the quadratic regression equation that served as the unconstrained equation for the squared difference score, as illustrated below:

$$
S=b_{0}+b_{1} D+b_{2} P+b_{3} D^{2}+b_{4} D P+b_{5} P^{2}+e
$$

In Equation 1, $D$ represents delivered inducements, $P$ represents promised inducements, and $S$ indicates satisfaction. We focused on differ- 
ent aspects of this equation depending on the hypothesis being tested. Hypothesis 3 predicted that, for pay, recognition, and relationships, satisfaction will increase as delivered terms increase toward promised levels and continue to increase as delivered terms exceed promised levels. This prediction corresponds to a positive slope along the breach line. The shape of a surface along the breach line is found by substituting the formula for this line (i.e., $P=-D$ ) into Equation 1 (Edwards \& Parry, 1993), which yields:

$$
S=b_{0}+\left(b_{1}-b_{2}\right) D+\left(b_{3}-b_{4}+b_{5}\right) D^{2}+e
$$

The term $\left(b_{3}-b_{4}+b_{5}\right)$ represents the curvature of the surface along the breach line, and the term $\left(b_{1}-b_{2}\right)$ represents the slope of the surface along the breach line at the point where $P$ and $D$ equal the mean of their means. Because Hypothesis 3 predicted a positive slope but no curvature along the breach line, we would expect a positive value for $\left(b_{1}-b_{2}\right)$ and a null value for $\left(b_{3}-b_{4}+b_{5}\right)$.

Hypothesis 4 predicted that, for variety, skill development, and career training, satisfaction will decrease as delivered inducements deviate from promised inducements in either direction. This hypothesis corresponds to an inverted U-shaped relationship along the breach line, which implies a negative value for the term $\left(b_{3}-b_{4}+b_{5}\right)$ in Equation 2. In isolation, Hypothesis 4 also suggests that satisfaction is greatest when promised and delivered inducements are equal, indicating a null value for $\left(b_{1}-b_{2}\right)$. However, this condition contradicts Hypothesis 6 , as we later explain. Thus, tests of Hypothesis 4 focused solely on the value of $\left(b_{3}-b_{4}+b_{5}\right)$.

Hypothesis 5 predicted that satisfaction would increase along the fulfillment line, which is defined by values where $P=D$. The shape of a surface along the fulfillment line is found by substituting its formula into Equation 1, which produces:

$$
S=b_{0}+\left(b_{1}+b_{2}\right) D+\left(b_{3}+b_{4}+b_{5}\right) D^{2}+e
$$

The term $\left(b_{3}+b_{4}+b_{5}\right)$ represents the curvature of the surface along the $P=D$ line, and the term $\left(b_{1}+b_{2}\right)$ indicates the slope of the surface along the $P=D$ line at the point where $P$ and $D$ both equal the mean of their means. Hypothesis 5 predicted a positive slope but no curvature along the fulfillment line, which would be evidenced by a positive value for $\left(b_{1}+b_{2}\right)$ and a null value for $\left(b_{3}+b_{4}+b_{5}\right)$ in Equation 3 .

Finally, Hypothesis 6 predicted that satisfaction would be more strongly related to delivered inducements than promised inducements. In effect, this hypothesis predicted that delivered inducements are given greater weight than promised inducements. As a result, the coefficients on $D$ and $D^{2}$ should be larger in absolute magnitude than the coefficients 
on $P$ and $P^{2}$, respectively, in Equation 1 (because $D P$ reflects both delivered and promised inducements, its coefficient should be largely unaffected by changing the relative weights of $D$ and $P$ ). For pay, recognition, and relationships, the predicted surface (Figure $2 \mathrm{c}$ ) entails a positive relationship for delivered inducements, a negative relationship for promised inducements, positive slope along the fulfillment line, and no curvilinearity. Therefore, greater weight for delivered inducements would be evidenced as $b_{1}>-b_{2}$ in Equation 1 . Note that this expression is equivalent to $b_{1}+b_{2}>0$, which captures the slope of the surface along the $P=D$ line predicted by Hypothesis 5 . Therefore, for pay, recognition, and relationships, the tests of whether the sum $b_{1}+b_{2}$ is greater than zero constitute evidence for both Hypotheses 5 and 6 . In contrast, the predicted surface for variety, skill development, and career training (Figure 3c) was curved downward along the breach line and positively sloped along the fulfillment line. As stated earlier, greater weight for delivered inducements relative to promised inducements shifted the maximum of the surface to the right along the breach line and rotated the surface counterclockwise. The shift is evidenced by $b_{1}>b_{2}$, and the rotation corresponds to $b_{3}>b_{5}$, as can be seen by applying formulas from Edwards and Parry (1993). The shift and rotation of the surface can also be tested based on the location of the first principal axis. Specifically, the shift of the surface along the breach line is found by substituting the equation for this line into the formula for the first principal axis and solving for $D$ (Edwards \& Parry, 1993). The result is $-p_{10} /\left(p_{11}+1\right)$, where $p_{10}$ and $p_{11}$ are the intercept and slope, respectively, of the first principal axis in the plane defined by promised and delivered inducements. $A$ counterclockwise rotation of the first principal axis would be indicated if the slope of the axis (i.e., $p_{11}$ ) is greater than one. These features of the first principal axis were computed using formulas presented by Edwards and Parry (1993), and confidence intervals for these features were derived using the bootstrap (Efron \& Tibshirani, 1993; Mooney \& Duval, 1993). For each inducement, we drew 10,000 bootstrap samples, estimated Equation 1 using each sample, and used the resulting coefficients to construct confidence intervals for response surface features using the percentile method with bias correction (Efron \& Tibshirani, 1993; Mooney \& Duval, 1993).

Prior to conducting the regression analyses, we centered each pair of promised and delivered contract terms at a common value midway between their means (Edwards, 1994). This scaling facilitated interpretation and ensured that the breach and fulfillment lines passed through the bulk of our data, which enhanced the statistical power of tests along these lines. 
TABLE 1

Descriptive Statistics, Reliability Estimates, and Correlations Among Measures

\begin{tabular}{|c|c|c|c|c|c|c|c|c|c|c|c|}
\hline & $M$ & $S D$ & 1 & 2 & 3 & 4 & 5 & 6 & 7 & 8 & 9 \\
\hline \multicolumn{12}{|l|}{$\begin{array}{c}\text { Algebraic } \\
\text { difference scores }\end{array}$} \\
\hline 1. Pay & -.057 & 1.057 & $(.686)$ & & & & & & & & \\
\hline 2. Recognition & .153 & 1.32 & .282 & $(.721)$ & & & & & & & \\
\hline 3. Relationships & .290 & 1.411 & .250 & .520 & $(.741)$ & & & & & & \\
\hline 4. Variety & -.178 & 1.224 & .311 & .340 & .379 & $(.670)$ & & & & & \\
\hline 5. Skill dev. & -.213 & 1.204 & .336 & .462 & .418 & .546 & (.635) & & & & \\
\hline 6. Career trng. & -.126 & 1.178 & .269 & .394 & .331 & .450 & .536 & $(.620)$ & & & \\
\hline \multicolumn{12}{|c|}{$\begin{array}{c}\begin{array}{c}\text { Squared } \\
\text { difference scores }\end{array} \\
\end{array}$} \\
\hline 7. Pay & 1.115 & 2.609 & -.239 & .068 & .062 & -.135 & .124 & .159 & $(.511)$ & & \\
\hline 8. Recognition & 1.758 & 3.103 & .205 & .343 & .287 & .039 & .062 & .186 & .084 & (.448) & \\
\hline 9. Relationships & 2.066 & 3.342 & .185 & .292 & .561 & .082 & .046 & $\begin{array}{r}.080 \\
-253\end{array}$ & .064 & .531 & $(.404)$ \\
\hline 10. Variety & 1.524 & 3.106 & -.110 & -.056 & -.140 & -.487 & -.303 & -.253 & .202 & .062 & .050 \\
\hline $\begin{array}{l}\text { 11. Skill dev. } \\
\text { 12. Career trng. }\end{array}$ & $\begin{array}{l}1.488 \\
1.398\end{array}$ & $\begin{array}{l}3.045 \\
3.010\end{array}$ & $\begin{array}{l}.056 \\
.119\end{array}$ & $\begin{array}{r}-.092 \\
.044\end{array}$ & $\begin{array}{r}-.080 \\
.038\end{array}$ & $\begin{array}{l}-.272 \\
-.118\end{array}$ & $\begin{array}{l}-.271 \\
-.209\end{array}$ & $\begin{array}{l}-.254 \\
-.146\end{array}$ & $\begin{array}{l}.107 \\
.051\end{array}$ & $\begin{array}{l}.221 \\
.242\end{array}$ & $\begin{array}{l}.114 \\
.154\end{array}$ \\
\hline \multicolumn{12}{|l|}{$\begin{array}{c}\text { Promised } \\
\text { inducements }\end{array}$} \\
\hline 13. Pay & 4.591 & 1.193 & -.357 & -.089 & -.119 & .079 & -.077 & -.025 & -.111 & -.203 & -.190 \\
\hline 14. Recognition & 4.443 & 1.357 & -.004 & -.294 & -.175 & .164 & .050 & -.030 & -.137 & -.344 & -.358 \\
\hline 15. Relationships & s 4.522 & 1.441 & -.094 & -.210 & -.356 & .094 & -.035 & -.086 & -.145 & -.300 & -.337 \\
\hline 16. Variety & 4.559 & 1.391 & -.124 & -.019 & -.154 & -.186 & -.138 & -.078 & .138 & -.129 & -.144 \\
\hline $\begin{array}{l}\text { 17. Skill dev. } \\
\text { 18. Career trng. }\end{array}$ & $\begin{array}{l}4.735 \\
4.043\end{array}$ & $\begin{array}{l}1.441 \\
1.557\end{array}$ & $\begin{array}{l}-.025 \\
-.004\end{array}$ & $\begin{array}{l}-.098 \\
-.051\end{array}$ & $\begin{array}{l}-.125 \\
-.112\end{array}$ & $\begin{array}{r}.001 \\
-.031\end{array}$ & $\begin{array}{l}-.216 \\
-.068\end{array}$ & $\begin{array}{l}-.014 \\
-.230\end{array}$ & $\begin{array}{l}-.120 \\
-.142\end{array}$ & $\begin{array}{l}-.135 \\
-.211\end{array}$ & $\begin{array}{l}-.093 \\
-.132\end{array}$ \\
\hline \multicolumn{12}{|l|}{$\begin{array}{c}\text { Delivered } \\
\text { inducements }\end{array}$} \\
\hline 19. Pay & 4.553 & 1.289 & .483 & .147 & .093 & .328 & .203 & .196 & -.300 & -.023 & -.026 \\
\hline 20. Recognition & 4.579 & 1.542 & .223 & .547 & .265 & .417 & .415 & .291 & -.065 & -.025 & -.078 \\
\hline 21. Relationships & 54.806 & 1.625 & .131 & .261 & .544 & .412 & .330 & .209 & -.077 & -.02 & .182 \\
\hline 22. Variety & 4.387 & 1.667 & .118 & .227 & .140 & .557 & .274 & .256 & .021 & -.081 & -.063 \\
\hline 23. Skill dev. & 4.520 & 1.606 & .206 & .226 & .171 & .372 & .486 & .352 & -.024 & -.079 & -.052 \\
\hline 24. Career trng. & 3.897 & 1.675 & .174 & .214 & .116 & .269 & .291 & .449 & -.025 & -.071 & -.068 \\
\hline 25. Satisfaction & 5.673 & 1.336 & .245 & .321 & .348 & .366 & .385 & .311 & -.123 & .001 & .066 \\
\hline
\end{tabular}

Treatment of missing data. To avoid problems with listwise deletion of missing data, we used a within-person mean imputation procedure (Roth, Switzer III, \& Switzer, 1999) in the following manner. When one value was missing from a 3 -item measure, the mean of the remaining two items from that respondent was substituted for the missing value. This procedure yielded a sample size that was $2 \%$ larger than would have resulted from listwise deletion.

Screening for outliers and influential observations. Tests of surface features based on Equations 1, 2, and 3 are susceptible to outliers and influential observations. To detect such observations, each regression equation was screened using studentized residuals, leverage, and Cook's $D$ statistics criteria. Observations that exceeded recommended cutoff val- 
TABLE 1 (continued)

\begin{tabular}{llllllllllllllll}
\hline 10 & 11 & 12 & 13 & 14 & 15 & 16 & 17 & 18 & 19 & 20 & 21 & 22 & 23 & 24 & 25 \\
\hline
\end{tabular}

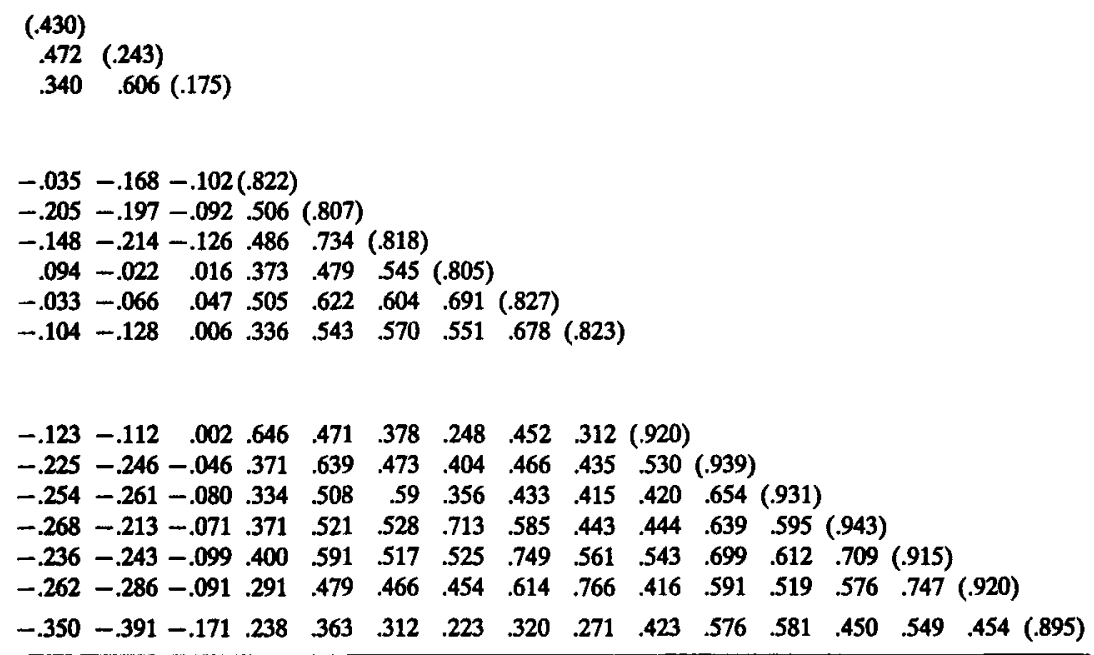

Note: $N=193$. Reliability estimates (Cronbach's alpha) are reported along the diagonal. Correlations greater than or equal to .20 were statistically significant $(p<.05)$

ues for all three criteria (Fox, 1991) and were clearly discrepant on plots that combined these criteria were discarded from the analysis. This procedure affected no more than seven cases for each equation.

Controlling Type I error. Hypotheses 1, 2, 5, and 6 were tested with six regression equations, and Hypotheses 3 and 4 were tested with three regression equations, representing the number of inducements corresponding to each hypothesis. To control Type I error, we applied the sequential Bonferroni procedure to tests of $R^{2}$ values for each set of regression equations to maintain a nominal alpha level of .05 for each hypothesis (Holm, 1979; Seaman, Levin, \& Serlin, 1991). For equations that satisfied the corrected alpha level yielded by this procedure, we 
tested the coefficients using the nominal alpha of .05 , thereby striking a balance between Type I and Type II error.

Power analysis. To determine whether our sample provided adequate statistical power, we conducted a power analysis for tests of the $R^{2}$ values from the regression equations. With alpha at .05 and a sample size of 200 (the minimum used in our analyses), power was .80 for detecting a $R^{2}$ value of .07 for the full quadratic equation. This value represents a small to moderate effect size for applications of polynomial regression in similar contexts (e.g., Edwards, 1996; Edwards \& Rothbard, 1999). Therefore, statistical power was adequate.

\section{Results}

\section{Descriptive statistics}

Descriptive statistics, reliability estimates, and correlations for all measures are reported in Table 1. Reliability estimates of promised and delivered inducements ranged from .805 to .943 with a median of .871. Using formulas provided by Edwards (1994) and Bohrnstedt and Marwell (1978), we computed reliability estimates for the algebraic and squared differences between promised and delivered inducements. Reliabilities for the algebraic differences ranged from .620 to .741 , and reliabilities for the squared differences ranged from .175 to .511 . In all cases, the reliabilities of the difference scores were lower than the reliabilities of the promised and delivered inducement measures that constituted the difference. Correlations between promised and delivered measures of the same inducement ranged from .590 to .766 , indicating that higher promised levels were accompanied by higher delivered levels. Satisfaction was positively correlated with delivered inducements and, to a lesser extent, promised inducements. Satisfaction was also positively correlated with the algebraic difference scores. In contrast, satisfaction was negatively correlated with the squared difference scores for variety, skill development, and career training and uncorrelated with the squared difference scores for pay, recognition, and relationships.

\section{Tests of Hypotheses Based on the Traditional View}

Algebraic difference scores. Table 2 presents results for the algebraic difference scores. These results indicate that, for all six inducements, the algebraic difference between delivered and promised inducements was positively related to satisfaction, implying support for Hypothesis 1. Confirmatory tests of the algebraic difference scores are also reported in Table 2. Consistent with the first condition, the $R^{2}$ values for the 
TABLE 2

Tests of Algebraic Difference and Direct Measure of Breach Models

\begin{tabular}{lllllllll}
\hline \hline & \multicolumn{6}{l}{ Constrained equation } & \multicolumn{6}{l}{ Unconstrained equation } \\
\cline { 2 - 7 } & $(D-P)$ & $R^{2}$ & $D$ & $P$ & $R^{2}$ & $F_{C}$ & $F_{H}$ \\
\hline Pay & $.249^{* *}$ & $.046^{* *}$ & $.403^{* * *}$ & -.018 & $.182^{* * *}$ & $33.144^{* * *}$ & 1.211 \\
Recognition & $.308^{* * *}$ & $.115^{* * *}$ & $.477^{* * *}$ & .001 & $.377^{* * *}$ & $85.195^{* * *}$ & $5.147^{* *}$ \\
Relationships & $.305^{* * *}$ & $.130^{* * *}$ & $.457^{* * *}$ & -.035 & $.357^{* * *}$ & $70.808^{* * *}$ & $4.025^{* * *}$ \\
Variety & $.396^{* * *}$ & $.171^{* * *}$ & $.452^{* * *}$ & $-.198^{* *}$ & $.268^{* * *}$ & $26.587^{* * *}$ & $2.846^{*}$ \\
Skill development & $.488^{* * * *}$ & $.197^{* * *}$ & $.587^{* * *}$ & $-.219^{* * *}$ & $.362^{* * *}$ & $51.914^{* * *}$ & $4.199^{* *}$ \\
Career training & $.365^{* * *}$ & $.135^{* * *}$ & $.459^{* * *}$ & $-.133^{* *}$ & $.245^{* * *}$ & $29.029^{* * *}$ & 1.480 \\
\hline
\end{tabular}

Notes: $N$ ranged from 201 to 206 . For columns labeled $(D-P), D$, and $P$, values represent unstandardized regression coefficients from equations where $D=$ delivered inducement and $P=$ promised inducement. The column $F_{C}$ presents $F$-ratios for the test of the constraints imposed by the algebraic difference score, i.e., $b_{1}=-b_{2}(d f, 1, N-3)$. The column $F_{H}$ presents $F$-ratios for the test of higher order terms in a quadratic equation, i.e., $D^{2}, D^{P}$, and $P^{2}(d f 3, N-5)$.

$* p<.05 \quad * * p<.01 \quad * * * p<.001$

unconstrained equations were significant for all six inducements. Regarding the second condition, the coefficient on delivered inducements was positive and significant for all six inducements, but the coefficient on promised inducements was negative and significant for only three inducements: variety, skill development, and career training. The third condition, which stipulates that $b_{1}=-b_{2}$, was rejected for all six inducements, as indicated by the $F$-tests reported in the $F_{C}$ column of Table 2. Finally, the fourth condition was rejected for recognition, relationships, variety, and skill development, as evidenced by the $F$-test for the higher-order terms $D^{2}, D P$, and $P^{2}$ reported in the column labeled $F_{H}$. Thus, the confirmatory conditions for the algebraic difference score were not met for any of the six inducements. Instead, these results suggest that satisfaction is primarily related to delivered inducements and may have curvilinear or interactive relationships with delivered and promised inducements, as indicated by the tests of higher-order terms. These findings are clarified by the polynomial regression analysis under the expanded view, as we later show.

Squared difference scores. Results for the squared difference scores are reported in Table 3. For variety, skill development, and career training, satisfaction was negatively correlated to the squared difference between promised and delivered inducements. These results suggest that satisfaction was greatest when delivered and promised inducements were equal and decreased as delivered and promised inducements differed in either direction, as predicted by Hypothesis 2 . Confirmatory tests of the squared difference scores reported in Table 3 showed that the first condition was met for all six inducements, as evidenced by significant $R^{2}$ values. The second condition required that the coefficients 


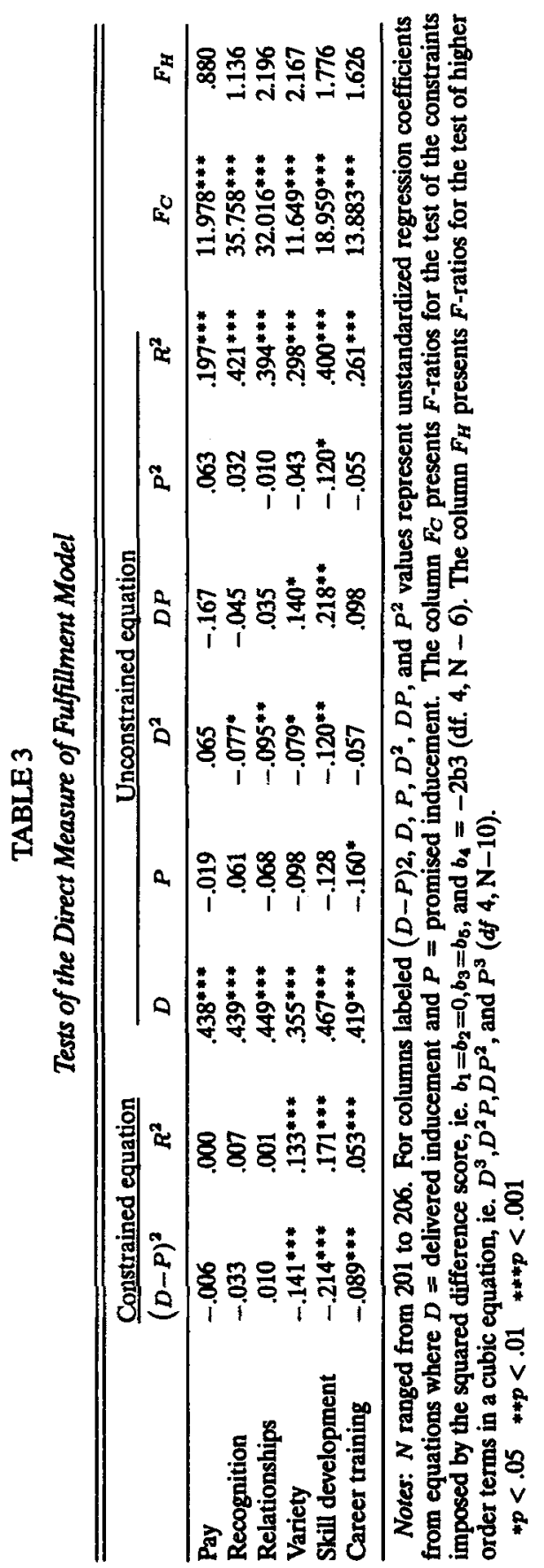


on $D$ and $P$ did not differ from zero, the coefficients on $D^{2}$ and $P^{2}$ were negative, and the coefficient on $D P$ was positive. This pattern was not met for any of the six inducements. The third condition, which entailed the constraints implied by the squared difference model (i.e., $b_{1}=0, b_{1}=0, b_{3}=b_{5}, b_{4}=-2 b_{3}$ ), was not satisfied for any of the six inducements, as shown by the $F$-tests in the $F_{C}$ column. Regarding the fourth condition, tests of higher orders terms (i.e., $D^{3}, D^{2} P, D P^{2}, P^{3}$ ) were not significant, as indicated by the $F$-tests reported in the $F_{H}$ column. In sum, the four confirmatory conditions were not met for any of the inducements. Rather, these results suggest that satisfaction is related to delivered inducements and, in some cases, has curvilinear relationships with delivered inducements, interactive relationships with delivered and promised inducements, or both. The meaning of these findings is clarified by the following analysis associated with the expanded view.

\section{Tests of the Expanded View Hypotheses}

Coefficients from polynomial regression analyses corresponding to the expanded view are reported in Table 3 , and combinations of coefficients pertaining to Hypotheses 3, 4, 5, and 6 are reported in Table 4.

Test of breach hypotheses for pay, recognition, and relationships. Hypothesis 3 predicted a positive linear slope along the breach line for pay, recognition, and relationships. Consistent with this prediction, surfaces for these three inducements were positively sloped along the breach line and exhibited no significant curvature, as indicated by the values listed under the columns labeled $b_{1}-b_{2}$ and $b_{3}-b_{4}+b_{5}$, respectively. Thus, Hypothesis 3 was supported.

Test of breach hypotheses for variety, skill development, and career training. Hypothesis 4 predicted an inverted $U$-shaped relationship along the breach line for variety, skill development, and career training. As predicted, results indicated that surfaces were curved downward along the breach line for variety, skill development, and career training, as evidenced by the negative values under the column labeled $b_{3}-b_{4}+b_{5}$. Hence, Hypothesis 4 received support for all three inducements.

Test of fulfillment hypotheses. For all six inducements, Hypothesis 5 predicted a positive slope along the fulfillment line for satisfaction. This prediction was supported for all six inducements, as shown by the positive values under the $b_{1}+b_{2}$ column. For recognition and relationships, the negative values under the $b_{3}+b_{4}+b_{5}$ column indicated that the surface was also curved downward along the fulfillment line. Further inspection revealed that the surface remained positively sloped throughout the range of the data. Thus, Hypothesis 5 was supported for all six inducements. 


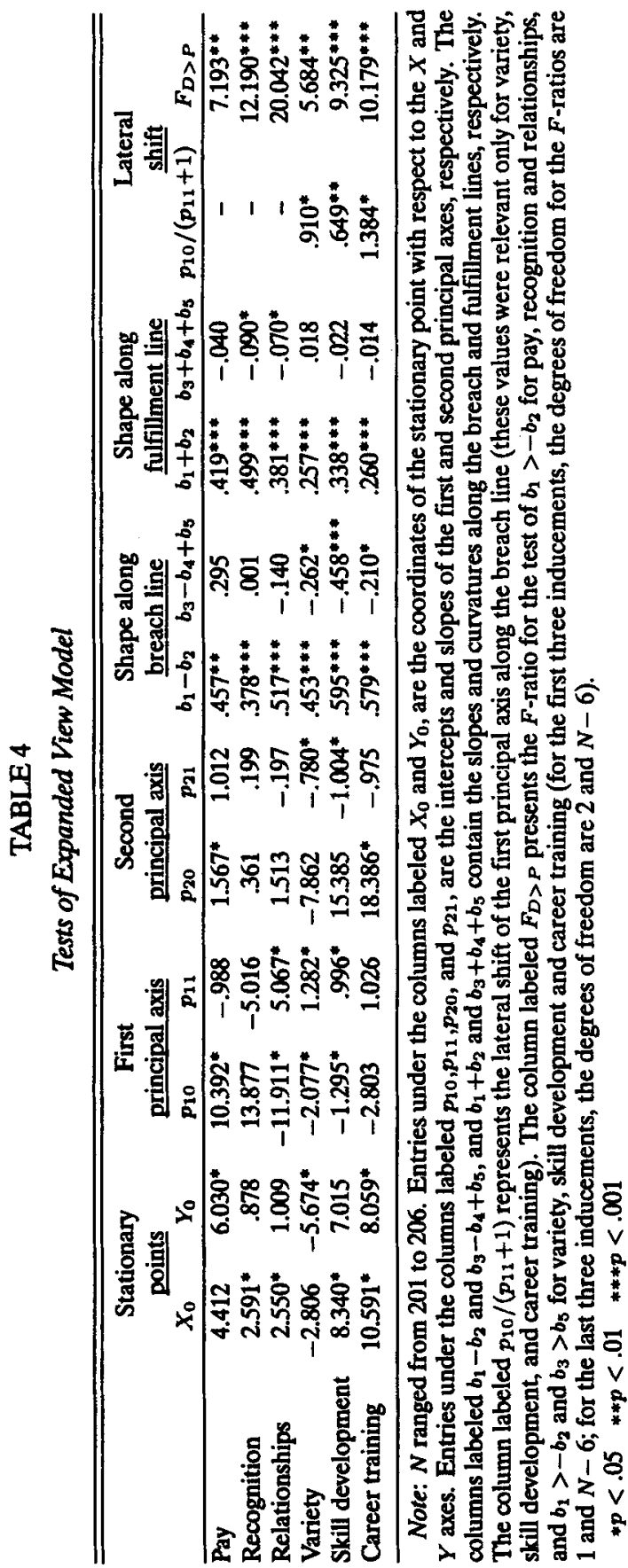


Test of relative effects of promised and delivered inducements. Hypothesis 6 predicted that satisfaction would be more strongly related to delivered inducements than to promised inducements. For pay, recognition, and relationships, evidence in support of Hypothesis 6 is indicated by $b_{1}>-b_{2}$, or $b_{1}+b_{2}>0$, in Equation 1 . This test is equivalent to the test of the slope of the breach line in Table 4, and the $F$-ratios for this test are reported in the column labeled $F_{D>P}$. As expected, these tests indicate that, for pay, recognition, and relationships, delivered inducements were more strongly related to satisfaction than promised inducements. For variety, skill development, and career training, Hypothesis 6 is supported if $b_{1}>b_{2}$ and by $b_{3}>b_{5}$. The $F$-ratios for the combined test of these conditions are presented under the column labeled $F_{D>P}$ and show that, as predicted, delivered inducements were more strongly related to satisfaction than promised inducements for variety, skill development, and career training. Separate tests indicated that, for all three inducements, $b_{1}$ was greater than $b_{2}$ but $b_{5}$ was not greater than $b_{3}$. These results were consistent with tests of the first principal axes for these inducements, which indicated that the axes were shifted to the right along the breach line (as indicated by the positive values under the column labeled $p_{10} /\left(p_{11-1}\right)$ ) and exhibited slopes that did not differ from unity (i.e., the $95 \%$ confidence interval for $p_{11}$ included 1.0). In combination, these findings indicated that the stronger effect for delivered inducements shifted the maximum of the surfaces along the breach line to the right but did not rotate the surfaces. In summary, for all six inducements, we found support for Hypothesis 6.

Illustrative surfaces. The foregoing results are illustrated in Figures 4 and 5 , which show surfaces relating satisfaction to promised and delivered inducements based on the quadratic regression equations reported in Table 3. We report surfaces for the full set of inducements but illustrate our results by focusing attention on the relationships between satisfaction and promised and delivered pay, and skill development, respectively. For pay, Figure $4 \mathrm{a}$, the surface is positively sloped along the breach line, indicating that satisfaction increases as delivered pay increases toward promised pay and continues to increase as delivered pay exceeds promised pay. ${ }^{1}$ The surface is also positively sloped along the fulfillment line, meaning that satisfaction is higher when promised and delivered pay are both high than when both are low. The values of $b_{1}$ and $b_{2}$ in Table 3 indicate that the positive slope along the fulfillment line is due almost exclusively to the positive coefficient for delivered pay. The

\footnotetext{
${ }^{1}$ In Figure 4, it may appear that the surfaces along the breach line for pay has positive curvature and that for recognition and relationships has negative curvature. Tests of these surfaces as indicated in Table 4 by the columns labeled $b_{1}-b_{2}$ and $b_{3}-b_{4}+b_{5}$, indicate positive slope with no significant curvature along the breach line.
} 


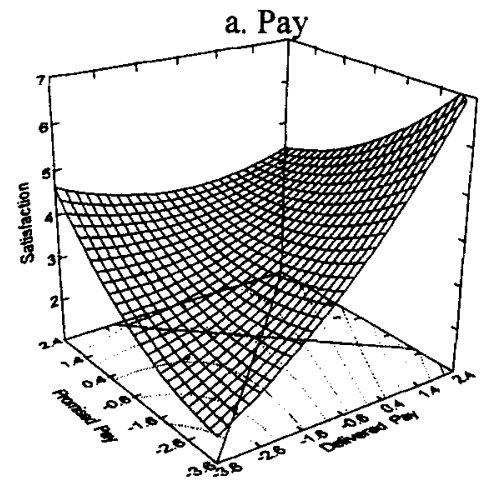

b. Recognition

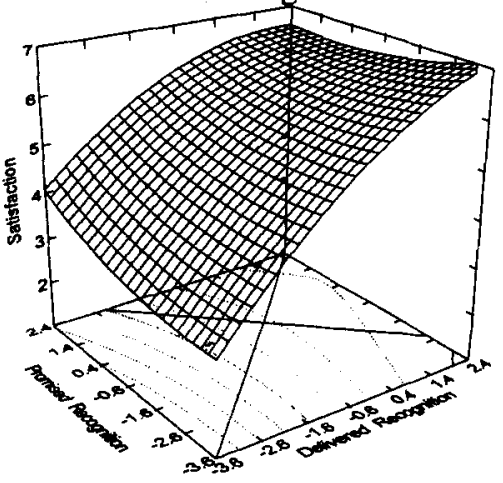

c. Relationships

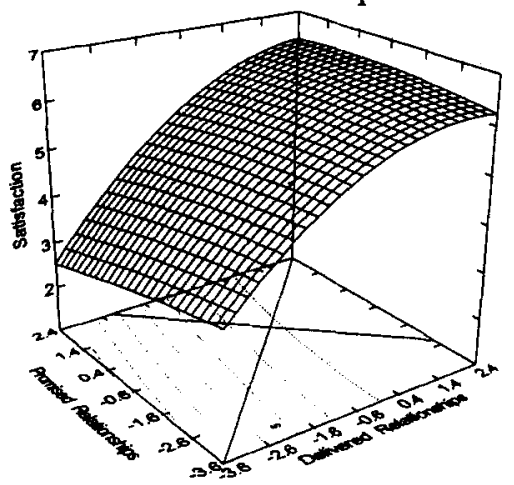

Figure 4: Surfaces Relating Satisfaction to Promised and Delivered Inducements for Pay, Recognition, and Relationships. 


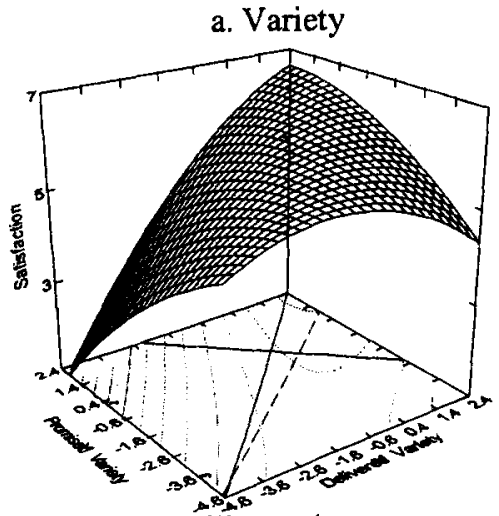

b. Skill Development

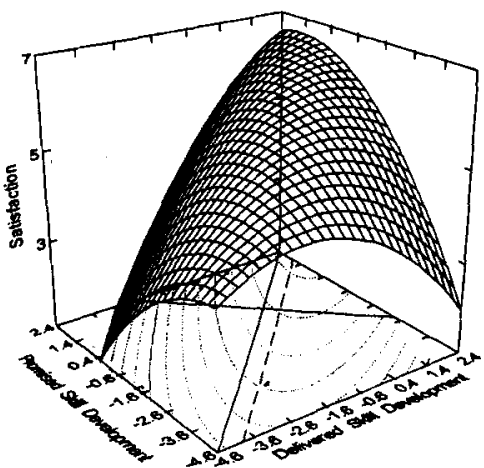

c. Career Training

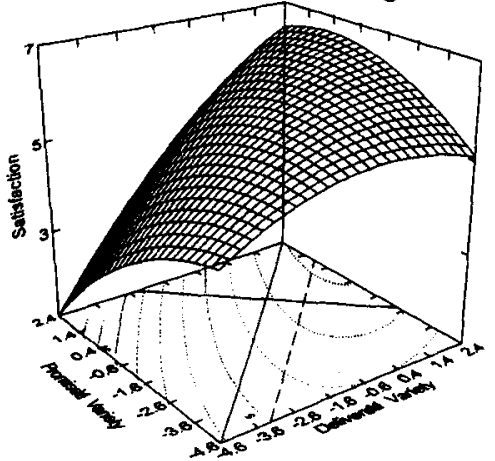

Figure 5: Surfaces Relating Satisfaction to Promised and Delivered Inducements for Variety, Skill Development, and Career Training 
positive slope along the fulfillment line also indicates that delivered pay is weighted more heavily than promised pay, which is again confirmed by the relative magnitudes of $b_{1}$ and $b_{2}$ in Table 3 .

For skill development, Figure $5 b$, the surface is curved downward along the breach line, indicating that satisfaction decreased as delivered variety deviated from promised variety in either direction. The decrease in satisfaction was somewhat stronger for deficient inducements than for excess inducements, given that satisfaction reached lower levels for deficiency than for excess. Satisfaction was also higher when promised and delivered skill development were both high than when both were low, as indicated by the positive slope along the fulfillment line. The surface was also shifted to the right along the breach line, indicating that delivered skill development was weighted more heavily than promised skill development. The surface was shifted but not rotated, which is evidenced in Table 3 by a greater value for $b_{1}$ than for $b_{2}$, but equivalent values for $b_{3}$ and $b_{5}$.

\section{Discussion}

This article articulated the assumptions of the traditional view of breach and fulfillment of psychological contracts and then presented an expanded view. The traditional view conceptualizes and measures breach and fulfillment by collapsing promised and delivered inducements into a single entity. This approach conceals important conceptual distinctions, confounds the effects of promised and delivered inducements, and imposes constraints on these effects that are untested and often contradictory. We set forth an expanded view of the psychological contract that retains delivered and promised inducements as separate constructs and examines their combined relationships with outcomes. This approach fully captures the effects of breach and fulfillment as well as the independent and relative effects of promised and delivered inducements on outcomes. Hypotheses developed from the traditional and expanded views were tested longitudinally in a sample of part-time employees by analyzing the relationships of promised inducements and delivered inducements with job satisfaction.

Our results demonstrated that the traditional view did not withstand scrutiny. Analyses that adopted the traditional view yielded mixed results regarding the relationship between breach and satisfaction, indicating that this relationship could be linear, curvilinear, or essentially flat. Moreover, these analyses adopted the assumption that satisfaction was constant when delivered and promised inducements were equal, regardless of whether they were at low or high levels. Polynomial regression showed that the constraints and assumptions of the traditional ap- 
proach were not supported and that the approach did not adequately account for the relationship of promised and delivered inducements with satisfaction.

Results from the expanded view revealed important aspects of the relationship of breach and fulfillment with satisfaction that were obscured by traditional view. These results showed that the effects of breach and fulfillment varied according to whether breach signified deficiency or excess, whether fulfillment was at low or high levels, and the substantive nature of the inducement. Consistent with conclusions from prior research (Robinson \& Morrison, 2000; Robinson \& Rousseau, 1994; Turnley \& Feldman, 2000), we found that satisfaction increased as deficiency was reduced, meaning that delivered inducements increased toward promised levels. These results suggest that promises constitute a relevant comparison standard (Atiyah, 1981; Goodman, 1974; Kulik \& Ambrose, 1992) such that employees who receive less than they were promised may feel that their needs are unmet and therefore experience dissatisfaction (Diener et al., 1999; Edwards et al., 1998; Locke, 1976).

The relationship between excess inducements and satisfaction appeared to depend on whether excess inducements inhibited or facilitated employees' need fulfillment. We reasoned that excess levels of pay, recognition, and relationships would be associated with increased satisfaction because these inducements may be applied to needs in multiple domains (Edwards et al., 1998; Locke, 1976). Consistent with this reasoning, satisfaction increased as delivered levels exceeded promised levels for these three inducements. For variety, skill development, and career training, we argued that excess levels can interfere with need fulfillment and, therefore, decrease satisfaction (Edwards et al., 1998; Locke, 1976; Warr, 1994). This reasoning was supported for all three inducements, suggesting that excess levels of these inducements lead to negative outcomes. The decrease in satisfaction was less pronounced for excess inducements than for deficient inducements, indicating that employees experienced greater dissatisfaction when variety, skill development, and career training fell short of promised levels than when they exceeded promised levels. These results clarify the ambiguous conclusions of the traditional view regarding the relationship between excess inducements and satisfaction and further show that this relationship depends on the nature of the inducement under consideration.

Regarding fulfillment, we found that employees who were promised and received low levels of inducements were less satisfied than employees who were promised and received high levels of inducements. These results support our predictions and are consistent with research indicating that setting and attaining ambitious standards promotes positive feelings such as competence and self-esteem (Brockner, 1988; White, 1959). 
However, our results refine this notion, indicating that the increase in satisfaction associated with fulfillment is primarily attributable to delivered inducements rather than promised inducements. These findings contradict a basis assumption of psychological contract theory that outcomes remain constant when delivered inducements match promised inducements irrespective of their absolute levels. Instead, our results indicate that outcomes are decidedly more positive at higher levels of delivered inducements.

Finally, our results show that satisfaction was more strongly related to delivered inducements than promised inducements. For pay, recognition, and relationships, satisfaction was largely a positive function of delivered inducements, irrespective of promised inducements. In contrast, for variety, skill development, and career training, the stronger relationship for delivered inducements indicated that satisfaction was maximized when delivered inducements were somewhat greater than promised inducements. Nonetheless, for these three inducements, promised inducements still served as an evaluative standard for delivered inducements, in that the maximum value of satisfaction for delivered inducements depended on the level of promised inducements. Overall, these results are consistent with prior research suggesting that, when evaluating their jobs, employees give greater weight to what they experience than what they prefer or expect (Edwards \& Rothbard, 1999; Hom et al., 1999; Irving \& Meyer, 1994). These results also challenge the notion that promised and delivered inducements contribute equally to breach and fufillment, as implied by methods used in traditional psychological contract research.

In summary, our results point to several important limitations of the traditional view of psychological contract research. In particular, our results indicate that neither the directional nor nondirectional versions of the traditional view adequately account for the relationship between breach and satisfaction. Our results also suggest that outcomes are not constant for fulfillment, irrespective of the absolute levels of delivered and promised inducements, and that delivered and promised inducement do not exert equal effects on outcomes. Moreover, our results indicate that the effects of breach are not the same for all types of inducements. These limitations can be addressed with the expanded view, which frames breach and fulfillment as the joint effects of delivered and promised inducements on outcomes and allows for the theoretical development and empirical testing of hypotheses regarding these joint effects. This study supported hypotheses derived using the expanded view, suggesting that it may provide a promising venue for future psychological contract research. 
Our findings also have practical implications that contradict recommendations derived from prior psychological contract research. Prior research has suggested that managers should carefully consider the promises they make to employees to avoid the negative consequences of deficient inducements (Lester et al., 2001; Robinson \& Morrison, 2000). Our results suggest that this prescription is incomplete, for several reasons. First, an employee's evaluations may stem primarily from delivered inducements, regardless of the inducements his or her manager has promised. Second, our results suggest that managers who make and keep promises made at low levels may not have satisfied employees. Third, reactions to excess inducements may depend on the type of inducement under consideration. Well meaning managers who intend to reward employees by exceeding promised levels of opportunities for development may inadvertently punish employees, leading to dissatisfaction and reduced motivation. Moreover, our findings that an employee's satisfaction may vary depending on the type of inducement involved may help explain the reasons behind unsuccessful attempts to restructure jobs. For example, newly enriched jobs offering increased variety may greatly exceed promised levels, leading to negative outcomes for employees and stymied organizational change efforts.

\section{Limitations}

This study has several limitations. First, our sample did not represent the general working population. Rather, it consisted of employees who were relatively young and may have felt limited involvement in their jobs. However, these features are likely to attenuate reactions to psychological contract breach and fulfillment. Therefore, the effects we found may be stronger in other samples. Second, there may have been some conceptual overlap among the inducements that we measured in the present study. Given that we studied actual employees and their work situations, it perhaps is not surprising that employees' inducements were related. However, the correlations among the delivered inducements were relatively high (average $r=.59$ ). In fact, when satisfaction was regressed on to the six delivered inducements, only recognition and relationships were significant $\left(R^{2}=.451\right)$. Although we selected inducements relevant to our sample, future research may identify a more parsimonious set of inducements. Third, because employees' perceptions of their contractual arrangements were of theoretical interest (Rousseau, 1989; Rousseau \& Parks, 1993), we used self-report measures. We recognize that selfreport measures introduce the possibility of bias due to common method variance. However, self-report measures appear to be most appropriate 
for introspectively experienced phenomena such as employees' perceptions of their job experiences (Crampton \& Wagner, 1994; Schalm \& Kelloway, 2001). Moreover, consistency effects often associated with relying on a single method should be lessened when data are collected longitudinally, as in our study. Finally, common method variance is unlikely to create nonlinear relationships such as those found in this study (Evans, 1985).

\section{Directions for Future Research}

Our study suggests several directions for future research. We examined a focused set of inducements that were relevant to our sample. Future studies should consider a broader array of psychological contract terms to extend the results reported here. Likewise, it would be informative to expand the set of outcomes beyond satisfaction to include other affective and behavioral consequences of breach and fulfillment. For instance, employees may respond to deficient inducements with anger (Robinson \& Morrison, 2000). On the other hand, excess inducements may increase satisfaction and pride when an employee believes he or she earned the excess inducements or induce guilt when an employee feels excess inducements were unearned (Weiss, Suckow, \& Cropanzano, 1999).

Future research should also directly examine the theoretical processes underlying the positive and negative effects of excess inducements. Our predictions regarding excess levels of inducements were based on the premise that excess pay, recognition, and relationships enhance need fulfillment, whereas excess variety, skill development, and career training inhibit need fulfillment. Although these predictions were supported, additional insight would be obtained by investigating the effects of excess inducements on the fulfillment of various needs. If excess inducements operate through need fulfillment, then the effects of these inducements on outcomes should diminish when need fulfillment is controlled.

Our findings on the effects of excess inducements may suggest new research directions for other theories in organizational behavior. For example, equity theory predicts that, as an employee's ratio of rewards to inputs increases, the employees' reactions become more positive (Adams, 1965). Positive evaluations may result when rewards correspond to the effects we found for pay, recognition, and relationships, but when rewards having the same effects as variety, skill development, and career training are involved, receiving high levels may lead to negative evaluations. Our results suggest that these effects may depend on the type of reward received, the absolute level of rewards, and, to a lesser extent, inputs. 
The expanded view developed here may be applied to examining outcomes of employees' promised and delivered contributions. Although excess contributions may produce stress and exhaustion (Cordes \& Dougherty, 1993; Moore, 2000), deficient contributions may have either positive or negative effects, depending on the specific contribution involved. For instance, deficient contributions may represent lower levels of demands and allow an employee to redirect their efforts to more personally rewarding activities. However, when contributions are tightly linked to either intrinsic or extrinsic rewards, deficient contributions may lead to boredom and lowered self-esteem in addition to dissatisfaction with the loss of desired rewards (Fisher, 1993; Goethals, Messick, \& Allison, 1991; Ryan \& Deci, 2000; Vroom, 1964). Moreover, future research should pursue the reciprocal effects of inducements and contributions, thereby capturing the exchange that defines the employment relationship (Simon, 1951).

The expanded view may also be applied to the employer's perspective, yielding a symmetric framework for investigating the relationship between employers and employees. With this framework, research can investigate inducements and contributions from the perspective of both the employer and employee to examine how each responds to breach and fulfillment of the psychological contract they hold for their counterpart.

Finally, substantial bodies of research point to different standards that employees may use to evaluate what they receive from their employers. These standards include the employee's own desires, what the employee thinks he or she deserves, what the employee had in the past or expects in the future, and what peers and coworkers receive (Adams, 1965; Berkowitz et al., 1987; Crosby, 1984; Michalos, 1985; Mowday, 1996; Rice et al., 1990; Sweeney, McFarlin, \& Inderrieden, 1990). It would be fruitful to integrate these standards along with promises to better understand how employees evaluate their experiences.

\section{REFERENCES}

Adams JS. (1965). Inequity in social exchange. In Berkowitz L (Ed.), Advances in experimental social psychology (pp. 267-299). New York: Academic Press.

Antonioni D, Park H. (2001). The effects of personality similarity on peer ratings of contextual work behaviors. PERSONNEL PSYCHOLOGY, 54, 331-360.

Atiyah PS. (1981). Promises, morals and law. Oxford: Clarendon Press.

Atwater LE, Ostroff C, Yammarino FJ, Fleenor JW. (1998). Self-other agreement: Does it really matter? PERSONNEL PSYCHOLOCY, 51, 577-598.

Bauer TN, Green SG. (1994). Effects of newcomer involvement in work-related activities: A longitudinal study of socialization. Journal of Applied Psychology, 79, 211-223.

Baumeister RF, Leary MR. (1995). The need to belong: Desire for interpersonal attachments as a fundamental human motivation. Psychological Bulletin, 117(3), 497-529.

Berkowitz L, Fraser C, Treasure FP, Cochran S. (1987). Pay, equity, job gratifications, and comparisons in pay satisfaction. Joumal of Applied Psychology, 72, 544-551. 
Bohrnstedt GW, Marwell G. (1978). The reliability of products of two random variables. Sociological Methodology, 9, 254-273.

Brockner J. (1988). Self-esteem at work: Research, theory, and practice. Lexington, MA: Lexington Books/D. C. Heath and Company.

Cohen S, McKay G. (1984). Social support, stress and the buffering hypothesis: A theoretical analysis. In Baum A, Taylor SE, Singer JE (Eds.), Handbook of psychology and health (pp. 253-267). Hillsdale, NJ: Erlbaum.

Cohen S, Wills TA. (1985). Stress, social support, and the buffering hypothesis. Psychological Bulletin, 98, 310-357.

Conway N, Briner RB. (2002). A daily diary study of affective responses to psychological contract breach and exceeded promises. Joumal of Organizational Behavior, 23, 287-302.

Cordes CL, Dougherty TW. (1993). A review and an integration of research on job burnout. Academy of Management Review, 18, 621-656.

Coyle-Shapiro JAM. (2002). A psychological contract perspective on organizational citizenship behavior. Joumal of Organizational Behavior, 23, 927-946.

Coyle-Shapiro JAM, Kessler I. (2000). Consequences of the psychological contract for the employment relationship: A large scale survey. Joumal of Management Studies, 37, 903-930.

Coyne JC, Downey G. (1991). Social factors and psychopathology: stress, social support, and coping processes. Annual Review of Psychology, 42, 401-425.

Crampton SM, Wagner JA. (1994). Percept-percept inflation in microorganizational research: An investigation of prevalence and effect. Joumal of Applied Psychology, 79, 67-76.

Crosby F. (1984). Relative deprivation in organizational settings. Research in Organizational Behavior, 6, 51-93.

Diener E, Suh EM, Lucas RE, Smith HL. (1999). Subjective well-being: Three decades of progress. Psychological Bulletin, 125, 276-302.

Edwards JR. (1991). Person-job fit: a conceptual integration, literature review, and methodological critique. In Cooper CL, Robertson IT (Eds.), International review of industrial and onganizational psychology (Vol. 6, pp. 283-357), Chichester, NY: Wiley.

Edwards JR. (1994). The study of congruence in organizational behavior research: Critique and a proposed alternative. Organizational Behavior and Human Decision Processes, 58(1), 51-101.

Edwards JR, Cable DM. (2002, August). Person-environment fit in onganizational behavior research: Toward a theory-testing approach. Paper presented at the 62nd Annual Meeting of the Academy of Management, Denver, $\mathrm{CO}$.

Edwards JR, Caplan RD, Harrison RV. (1998). Person-environment fit theory: conceptual foundations, empirical evidence, and directions for future research. In Cooper CL (Ed.), Theories of organizational stress (pp. 28-67). Oxford: Oxford University Press.

Edwards JR, Harrison RV. (1993). Job demands and worker health: Three-dimensional reexamination of the relationship between person-environment fit and strain. Journal of Applied Psychology, 78, 628-648.

Edwards JR, Parry ME. (1993). On the use of polynomial regression equations as an alternative to difference scores in organizational research. Academy of Management Journal, 36, 1577.

Edwards JR, Rothbard NP. (1999). Work and family stress and well-being: An examination of person-environment fit in the work and family domains. Organizational Behavior and Human Decision Processes, 77(2), 85-129. 
Efron B, Tibshirani R. (1993). An introduction to the bootstrap. New York: Chapman and Hall.

Evans MG. (1985). A Monte Carlo study of the effects of correlated method variance in moderated multiple regression analysis. Organizational Behavior and Human Decision Processes, 36(3), 305-323.

Fisher CD. (1993). Boredom at work: A neglected concept. Human Relations, 46, 395417.

Fox J. (1991). Regression diagnostics. Newbury Park, CA: Sage.

Gay EG, Weiss DJ, Hendel DD, Dawis, RV, Lofquist LH. (1971). Manual for the Minnesota Importance Questionnaire (Vol. 28 [bulletin no. 54]): Minnesota Studies in Vocational Rehabilitation.

Goethals GR, Messick DM, Allison ST. (1991). The uniqueness bias: studies of constructive social comparison. In Suls J, Wills TA (Eds.), Social comparison: Contemporary theory and research (pp. 149-176). Hillsdale, NJ: Erlbaum.

Goodman PS. (1974). An examination of referents used in the evaluation of pay. Onganizational Behavior and Human Decision Processes, 12(2), 170-195.

Gouldner AW. (1960). The norm of reciprocity: A preliminary statement. American Sociological Review, 25(2), 161-178.

Greenberg MS. (1980). A theory of indebtedness. In Gergen KJ, Greenberg MS, Willis RH (Eds.), Social exchange: advances in theory and research (pp. 3-26). New York: Plenum Press.

Guest DE, Conway N. (2002). Communicating the psychological contract: An employer perspective. Human Resource Management Joumal, 12(2), 22-38.

Guzzo RA, Noonan KA, Elron E. (1994). Expatriate managers and the psychological contract. Joumal of Applied Psychology, 79, 617-626.

Hackman JR, Oldham GR. (1975). Development of the job diagnostic survey. Journal of Applied Psychology, 60, 159-170.

Hagerty MR. (2000). Social comparisons of income in one's community: Evidence from national surveys of income and happiness. Journal of Personality and Social Psychology, 78, 764-771.

Herriot P, Manning WEG, Kidd JM. (1997). The content of the psychological contract. British Joumal of Management, 8(2), 151-162.

Holm S. (1979). A simple sequentially rejective multiple test procedure. Scandinavian Joumal of Statistics, 6, 65-70.

Hom PW, Griffeth RW, Palich LE, Bracker JS. (1999). Revisiting met expectations as a reason why realistic job previews work. PERSONNEL PSYCHOLOGY, 52, 97-112.

Hulin CL, Blood MR. (1968). Job enlargement, individual differences, and worker responses. Psychological Bulletin, 69, 41-55.

Imparato N. (1972). Relationship between Porter's Need Satisfaction Questionnaire and the Job Descriptive Index. Joumal of Applied Psychology, 56, 397-405.

Irving PG, Meyer JP. (1994). Reexamination of the met-expectations hypothesis: A longitudinal analysis. Joumal of Applied Pychology, 79, 937-949.

Johns G. (1981). Difference score measures of organizational behavior variables: A critique. Onganizational Behavior and Human Performance, 27, 443-463.

Judge TA, Thoresen CJ, Bono JE, Patton GK. (2001). The job satisfaction-job performance relationship: A qualitative and quantitative review. Psychological Bulletin, $127,376-407$.

Kickul J. (2001). When organizations break their promises: Employee reactions to unfair processes and treatment. Joumal of Business Ethics, 29, 289-307.

Kickul J, Lester SW, Finkl J. (2002). Promise breaking during radical organizational change: Do justice interventions make a difference? Joumal of Organizational Behavior, 23, 469-488. 
Kossek EE, Roberts K, Fisher S, Demarr B. (1998). Career self-management: A quasiexperimental assessment of the effects of a training intervention. PERSONNEL PSYCHOLOOY, 51, 935-962.

Kramer RM. (1999). Thust and distrust in organizations: Emerging perspectives, enduring questions. Annual Review of Psychology, 50, 569-598.

Kulik CT, Ambrose ML. (1992). Personal and situational determinants of referent choice. Academy of Management Review, 17, 212.

Larwood L, Wright TA, Desrochers S, Dahir V. (1998). Extending latent role and psychological contract theories to predict intent to turnover and politics in business organizations. Group and Organization Management, 23(2), 100-123.

Lawler EE. (1971). Pay and organizational effectiveness: A psychological view. New York: McGraw-Hill.

Lawler EE. (1981). Pay and onganization development. Reading, MA: Addison-Wesley.

Lester SW, Turnley WH, Bloodgood JM, Bolino MC. (2001). Not seeing eye to eye: differences in supervisor and subordinate perceptions of and attributions for psychological contract breach. Journal of Organizational Behavior, 23, 39-56.

Locke EA. (1976). The nature and causes of job satisfaction. In Dunnette M (Ed.), Handbook of industrial and onganizational psychology (pp. 1297-1350). Chicago: Rand McNally.

Mayer RC, Davis JH, Schoorman FD. (1995). An integrative model of organizational trust. The Academy of Management Review, 20, 709.

Michalos AC. (1985). Multiple discrepanies theory (MDT). Social Indicators Research, 16, $347-413$.

Miller S. (1981). Predictabiity and human stress: toward a clarification of evidence and theory. In Berkowitz L (Ed.), Advances in experimental social psychology (Vol. 14, pp. 203-256). New York: Academic Press.

Mooney CZ, Duval RD. (1993). Bootstrapping: A nonparametric approach to statistical inference, (Vol. 95), Newbury Park, CA: Sage.

Moore JE. (2000). Why is this happening? A causal attribution approach to work exhaustion consequences. Academy of Management Review, 25, 335-349.

Morrison EW. (1993). Longitudinal study of the effects of information seeking on newcomer socialization. Joumal of Applied Psychology, 78, 173-183.

Mowday RT. (1996). Equity theory predictions of behavior in organizations. In Steers RM, Porter LW, Bigley GA (Eds.), Motivation and leadership at work, 6th ed. (pp. 8-33). New York: McGraw-Hill.

Organ DW, Ryan K. (1995). A meta-analytic review of attitudinal and dispositional predictors of organizational citizenship behavior. PERSONNEL PSYCHOLOOY, 48, 775.

Pinder CC. (1998). Work motivation in organizational behavior. Upper Saddle River, NJ: Prentice Hall.

Porter LW, Pearce JL, Tripoli AM, Lewis KM. (1998, Special Issue). Differential perceptions of employers' inducements: Implications for psychological contracts. Joumal of Organizational Behavior, 19, 769-782.

Pryor RGL (1983). Manual for the work aspect preference scale. Melbourne: Australian Council for Education Research.

Rice RW, Phillips SM, McFarlin DB. (1990). Multiple discrepancies and pay satisfaction. Joumal of Applied Pyychology, 75, 386-393.

Robinson SL. (1996). Trust and breach of the psychological contract. Administrative Science Quarterty, 41, 574.

Robinson SL, Kraatz MS, Rousseau DM. (1994). Changing obligations and the psychological contract: A longitudinal study. Academy of Management Journal, 37, 137. 
Robinson SL, Morrison EW. (1995). Psychological contracts and OCB: The effect of unfulfilled obligations on civic virtue behavior. Joumal of Organizational Behavior, 16, 289-298.

Robinson SL, Morrison EW. (2000). The development of psychological contract breach and violation: A longitudinal study. Joumal of Organizational Behavior, 21, 525-546.

Robinson SL, Rousseau DM. (1994). Violating the psychological contract: Not the exception but the norm. Journal of Onganizational Behavior, 15, 245-259.

Roth PL, Switzer III FS, Switzer DM. (1999). Missing data in multiple item scales: A Monte Carlo analysis of missing data techniques. Organizational Research Methods, 2, 211-232.

Rousseau DM. (1989). Psychological and implied contracts in organizations. Employee Responsibilities and Rights Journal, 2(2), 121-139.

Rousseau DM. (1997). Organizational behavior in the new organizational era. Annual Review of Psychology, 48, 515-546.

Rousseau DM, Parks JM. (1993). The contracts of individuals and organizations. Research in organizational behavior, 15, 1-43.

Rousseau DM, Schalk R. (2000). Psychological contracts in employment: Cross-national perspectives. Thousand Oaks, CA: Sage.

Rousseau DM, Tijoriwala SA. (1998). Assessing psychological contracts: Issues, alternatives and measures. Journal of Organizational Behavior, 19, 679-695.

Ryan RM, Deci EL. (2000). Self-determination theory and the facilitation of intrinsic motivation, social development, and well-being. American Psychologist, 55(1), 68-78.

Schalm RL, Kelloway EK. (2001). The relationship between response rate and effect size in occupational health psychology research. Journal of Occupational Health Psychology, 6(2), 160-163.

Seaman MA, Levin JR, Serlin RC. (1991). New developments in pairwise multiple comparisons: Some powerful and practicable procedures. Psychological Bulletin, 110, 577-586.

Simon HA. (1951). A formal theory of the employment relationship. Econometrica, 19, 293-305.

Smith PC, Kendall LM, Hulin CL. (1969). The measurement of satisfaction in work and retirement: a strategy for the study of attitudes. Chicago: Rand McNally.

Stajkovic AD, Luthans F. (2001). Differential effects of incentive motivators on work performance. Academy of Management Joumal, 44, 580-590.

Sullivan SE. (1999). The changing nature of careers: $A$ review and research agenda. Joumal of Management, 25, 457-484.

Super DE. (1970). Work values inventory. Boston: Houghton-Mifflin.

Sweeney PD, McFarlin DB, Inderrieden EJ. (1990). Using relative deprivation theory to explain satisfaction with income and pay level: a multistudy examination. Academy of Management Journal, 33, 423-436.

Turnley WH, Bolino MC, Lester SW, Bloodgood JM. (2003). The impact of psychological contract fulfillment on the performance of in-role and organizational citizenship behaviors. Journal of Management, 29, 187-206.

Turnley WH, Feldman DC. (1999). The impact of psychological contract violations on exit, voice, loyalty, and neglect. Human Relations, 52, 895-922.

Turnley WH, Feldman DC. (2000). Re-examining the effects of psychological contract violations: unmet expectations and job dissatisfaction as mediators. Joumal of Organizational Behavior, 21, 25-42.

Tversky A, Griffin D. (1991). Endowment and contrast in judgments of well-being. In Strack F, Argyle M, Schwarz N (Eds.), Subjective well-being: An interdisciplinary perspective (pp 101-118). Elmsford, NY: Pergamon Press.

Vroom VH. (1964). Work and motivation. New York: Wiley. 
Warr P. (1987). Work, unemployment and mental health. Oxford: Clarendon Press.

Warr P. (1990). Decision latitude, job demands, and employee well-being. Work and Stress, 4(4), 285-294.

Warr P. (1994). A conceptual framework for the study of work and mental health. Work and Stress, 8(2), 84-97.

Welbourne TM, Johnson DE, Erez A. (1998). The role-based performance scale: Validity analysis of a theory-based measure. Acadmey of Management Joumal, 41, 540-555.

Weiss HM, Cropanzano R. (1996). Affective Events Theory: A theoretical discussion of the structure, causes and consequences of affective experiences at work. In Staw BM, Cummings LL (Eds.), Research in organizational behavior, 18, 1-74.

Weiss HM, Suckow K, Cropanzano R. (1999). Effects of justice conditions on discrete emotions. Journal of Applied Psychology, 84, 786-794.

White RW. (1959). Motivation reconsidered: The concept of competence. Psychological Review, 66, 297-333. 